\title{
Gravity Anomalies, Regional Elevation, and the Deep Structure of the North Atlantic
}

\author{
James R. Cochran and Manik Talwani
}

Lamont-Doherty Geological Observatory, Columbia University, Palisades, New York 10964

\begin{abstract}
The pattern of depth and gravity anomalies in the North Atlantic Ocean was examined by using $1^{\circ} \times 1^{\circ}$ and $5^{\circ} \times 5^{\circ}$ averages. The gravity field is dominated by two features: a broad high in the northern and central portion of the ocean and a large area of very negative anomalies in the western basin. The negative anomaly in the western North Atlantic has no expression in residual depth anomalies and does not appear to be related to surface features. The North Atlantic Gravity High is bounded on the south by an important and distinct boundary near $30^{\circ} \mathrm{N}$ which is present in both depth and gravity anomalies. North of this latitude, residual gravity anomalies (corrected for the 'ridge anomaly') take the form of a very broad high of about $20 \mathrm{mGal}$ with the values along isochrons nearly constant from $30^{\circ} \mathrm{N}$ to at least as far north as $75^{\circ} \mathrm{N}$. The depths within this region are consistently shallow with $5^{\circ} \times 5^{\circ}$ average residual depth anomalies which vary greatly from a few hundred meters near the Charlie Gibbs fracture zone to a few thousand meters near Iceland and the Azores. We used three-dimensional spherical earth models to investigate simple compensated mass distributions which could explain the observed depth and gravity anomalies. The acceptable family of models has the common characteristics that within the anomalous region north of the $30^{\circ} \mathrm{N}$ boundary a portion of the compensation must be distributed to depths of several hundred kilometers and that this deep mass deficiency must be nearly uniform throughout the area. However, the compensation for more local features within this region must be shallow (within the lithosphere). Thus the topographic highs surrounding Iceland and the Azores are compensated within the lithosphere, but the overall elevation is maintained at some greater depth by a mass deficiency in the asthenosphere. This mass deficiency can be explained by an increase in temperature of about $75^{\circ} \mathrm{C}$. Thus the gravity data enable us to establish the presence of a very large upper mantle hot spot that might be associated with the broad overall compensation of the entire North Atlantic north of $30^{\circ} \mathrm{N}$. Whether this upper mantle hot spot is associated with a deep mantle plume is uncertain, since the gravity effect of a plume is undetectable. However, its presence suggests that the immediate source of the unusual amount of material erupted at Iceland and the Azores is within the upper mantle.
\end{abstract}

\section{INTRODUCTION}

When it is compared with other oceans, the North Atlantic exhibits an unusual pattern of oceanic depths and gravity anomalies. Cochran and Talwani [1977] examined $5^{\circ} \times 5^{\circ}$ average gravity anomalies and residual depth anomalies (the depth expected for ocean floor of a given age minus the observed basement depths corrected for sediment loading) throughout the world's oceans. They found that the $5^{\circ} \times 5^{\circ}$ depth anomalies are generally less than about $500 \mathrm{~m}$, with larger positive values found mainly surrounding regions of extensive past or present volcanism away from the midocean ridge, such as the Hawaiian Swell. In these regions the topographic swell is usually about $1000-1500 \mathrm{~km}$ across and is found to be associated with a positive gravity anomaly of comparable extent. A large portion of the North Atlantic is also associated with large positive depth anomalies. This is most obvious at Iceland, where the Mid-Atlantic Ridge protrudes above sea level, but the unusually shallow area extends well north of Iceland into the Norwegian-Greenland Sea and south beyond the Azores to a distinct boundary near $30^{\circ} \mathrm{N}$.

The same region north of $30^{\circ} \mathrm{N}$ in the Atlantic is characterized by large positive free air gravity anomalies (see Figures 1 and 2) and is thus one of the few areas in the world's oceans where a large long-wavelength $(\lambda>$ several thousand kilometers) feature of the earth's gravity field is associated with a corresponding area of unusual depths [Cochran and Talwani, 1977]. The other area in which Cochran and Talwani [1977] noted such a correlation is a region in the southwestern Indian Ocean. There, positive regional gravity anomalies of the order of $20 \mathrm{mGal}$ are found over an area of shallow depths. Although the data are sparse, the region appears to be less

Copyright (c) 1978 by the American Geophysical Union. extensive than the unusual area in the Atlantic and to have maximum depth anomalies of about $700 \mathrm{~m}$.

Talwani and Le Pichon [1969] noted an apparent strong correlation between regional gravity anomalies and bathymetry in the North Atlantic. They considered the effect on the gravity field of isostatically compensating the $5^{\circ} \times 5^{\circ}$ average topography and concluded that shallow compensation results in isostatic anomalies consistently of one sign and in excess of $10 \mathrm{mGal}$ over areas of several million square kilometers. Their conclusion was that the 'isostatic mechanism operates to great depths in the upper mantle' and that there are also 'additional lateral inhomogeneities in the upper mantle which are nonisostatic in character' [Talwani and Le Pichon, 1969, p. 346]. The lateral inhomogeneities were necessary to explain the large negative gravity anomalies along the western margin of the Atlantic which are not related to the regional topography.

Sclater et al. [1975] argue that gravity and depth anomalies in the North Atlantic are directly correlated and result from the response of the lithosphere to convective flow in the asthenosphere. They compared $5^{\circ} \times 5^{\circ}$ average free air gravity anomalies and residual depth anomalies between $10^{\circ}$ and $50^{\circ} \mathrm{N}$ to the east of $50^{\circ} \mathrm{W}$ and noted a good visual correlation and satisfactory statistical correlation with the slope predicted by the numerical models of McKenzie et al. [1974].

Cochran and Talwani [1977], using more gravity data than were available to Sclater et al. [1975], pointed out that there is a correlation between gravity and depth in some areas of the North Atlantic in the sense that both are quite positive over similar areas. However, a direct relationship does not hold over the entire North Atlantic. They suggested that the correlation observed by Sclater et al. [1975] is largely due to two effects. One is the presence of regions of unusual elevation and relatively high gravity surrounding areas of extensive vol- 


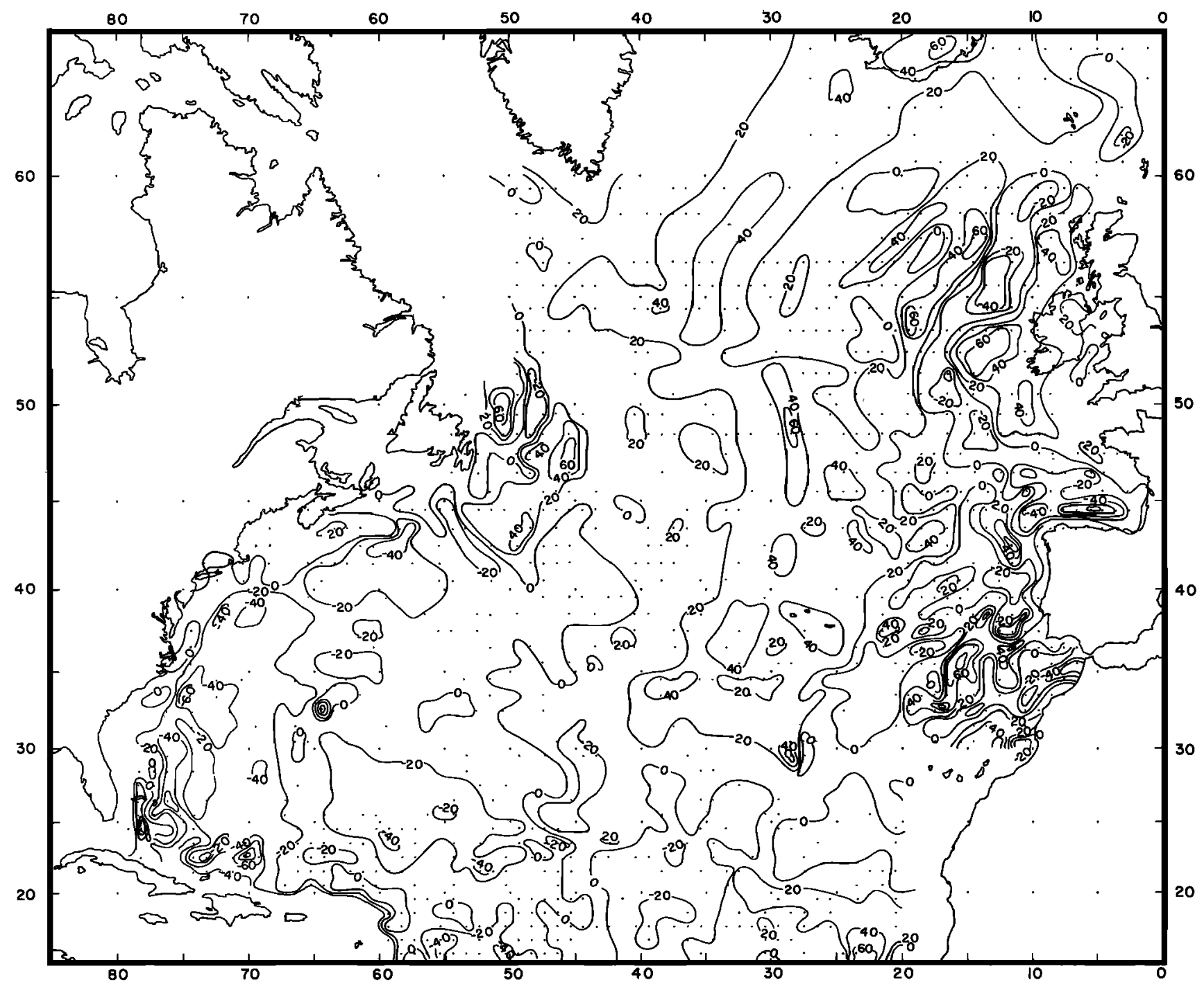

Fig. 1a. Map of the $1^{\circ} \times 1^{\circ}$ average free air gravity anomalies in the North Atlantic, contoured at 20-mGal intervals. Anomalies are referred to the hydrostatic figure of the earth (flattening, 1/299.7). Data points are indicated by dots. Values north of $60^{\circ} \mathrm{N}$ are $1^{\circ} \times 2^{\circ}$ averages.

canism away from the midocean ridge at the Canary Islands, Madeira, and the Cape Verde Islands, all of which are in the area considered by Sclater et al. [1975]. The second is the transition from the anomalous region of the North Atlantic Gravity High to more 'normal' areas. Thus gravity and depth both fall off west of the Azores and at the $30^{\circ} \mathrm{N}$ boundary. The gravity does not, however, fall off with the depth north of the Azores.

The purpose of this study is to examine the gravity anomalies and depths in the entire North Atlantic to find what patterns exist and quantitatively investigate how they might arise. We will be particularly interested in the area of the MidAtlantic Ridge north of $30^{\circ} \mathrm{N}$ in which positive gravity anomalies and shallow depths are found.

\section{$1^{\circ} \times 1^{\circ}$ AND $5^{\circ} \times 5^{\circ}$ Free Air Gravity AnOmalies}

We have compiled $1^{\circ} \times 1^{\circ}$ average free air gravity anomalies over the North Atlantic and present these data in Figure 1. The $1^{\circ} \times 1^{\circ}$ averages are combined to form $5^{\circ} \times 5^{c}$ averages which are shown in Figure 2. The $5^{\circ} \times 5^{\circ}$ field was sampled at $1^{\circ}$ intervals provided that at least $131^{\circ} \times 1^{\circ}$ averages were present within a $5^{\circ} \times 5^{\circ}$ square. The sources of data and method of obtaining the averages are discussed in Cochran and Talwani [1977], and the values are tabulated there.

The gravity anomalies in Figures 1 and 2 and throughout this study are referred to the hydrostatic figure of the earth (flattening, 1/299.7). This ellipsoid was chosen because it represents the stress free figure of the earth and departures from it must be supported in some manner. The difference between various ellipsoids appears as a slowly varying level change, and the choice of a particular reference ellipsoid will thus affect only the longest-wavelength anomalies. Talwani et al. [1972] present a plot of the difference between the hydrostatic, best fitting, and international reference ellipsoids as a function of latitude.

The most prominent large-scale features of the free air gravity anomaly maps are a gravity high over the Mid-Atlantic Ridge crest and the pronounced asymmetry of the field with respect to the Mid-Atlantic Ridge. The gravity anomalies in the eastern basin tend to be near zero or slightly negative, while large negative values are found in the western basin. Anomalies of the order of $-30 \mathrm{mGal}$ are found over much of the Nares, Hatteras, and Demerara Abyssal plains. The most negative $1^{\circ} \times 1^{\circ}$ average anomalies are found over the Hat- 


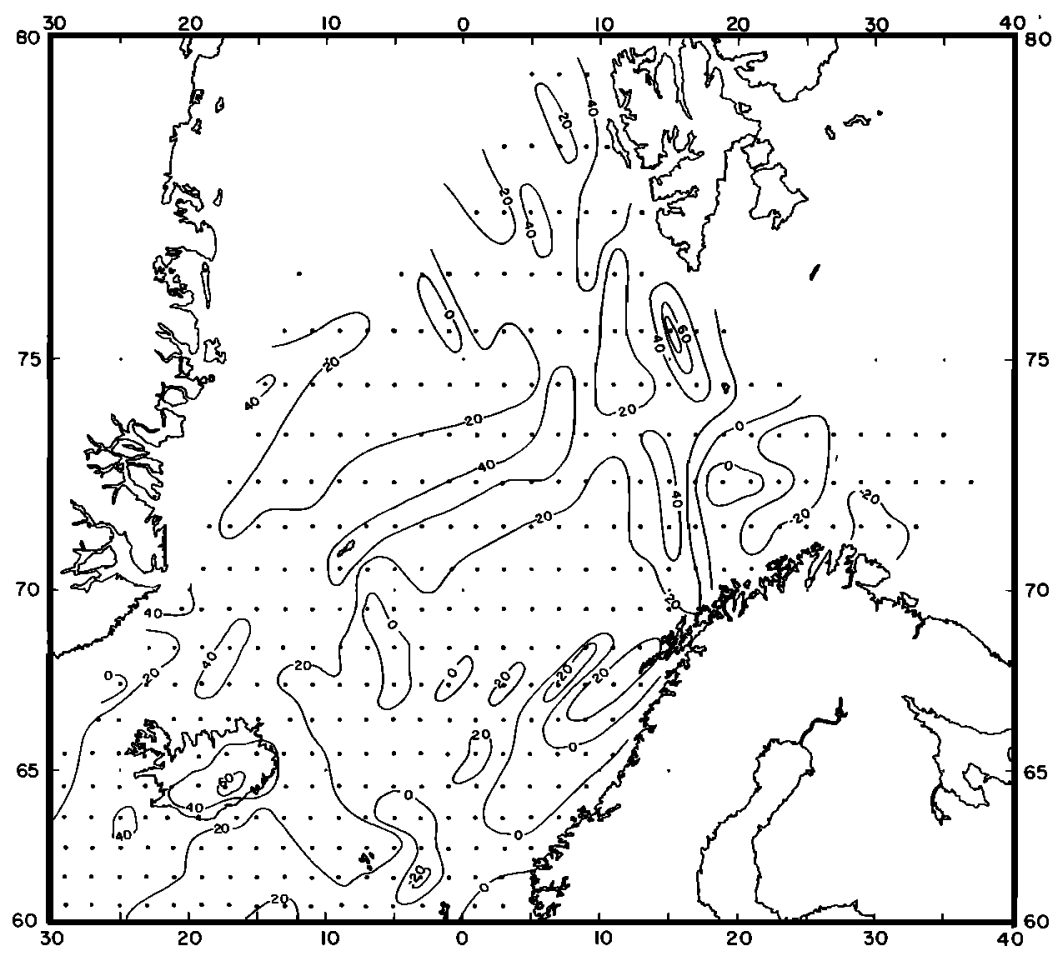

Fig. 1b. Map of the $1^{\circ} \times 2^{\circ}$ average free air gravity anomalies in the Norwegian-Greenland Sea contoured at 20-mGal intervals. Anomalies are referred to the hydrostatic figure of the earth (flattening, 1/299.7). Data points are indicated by dots.

teras Abyssal Plain southeast of Cape Hatteras and reach values of about $-60 \mathrm{mGal}$. The area of negative anomalies is interrupted near $65^{\circ} \mathrm{W}$ by a north-south trending relative gravity high over the Bermuda Rise.

The crest of the Mid-Atlantic Ridge is also the peak of a gravity high in the $1^{\circ} \times 1^{\circ}$ average anomalies. Even at the Azores, where a gravity high is centered just off the ridge crest over the islands (near $27.5^{\circ} \mathrm{W}$ ), there is another distinct maximum over the ridge crest (centered near $32^{\circ} \mathrm{W}$ ). The $1^{\circ} \times 1^{\circ}$ average free air anomalies over the ridge crest are close to zero in the southern part of the map. The anomalies over the ridge crest increase to about $20 \mathrm{mGal}$ north of the Kane fracture zone near $24^{\circ} \mathrm{N}$ and then increase again to about $40 \mathrm{mGal}$ between $30^{\circ}$ and $35^{\circ} \mathrm{N}$. They generally remain in the range of $40-50 \mathrm{mGal}$ from about $33^{\circ} \mathrm{N}$ to the northern limit of our data at $80^{\circ} \mathrm{N}$ (Figure 1). The largest $1^{\circ} \times 1^{\circ}$ average free air anomaly over the ridge crest is $63 \mathrm{mGal}$ at $48.5^{\circ} \mathrm{N}$. The $1^{\circ} \times$ $1^{\circ}$ average gravity anomalies reach $68 \mathrm{mGal}$ in southeastern Iceland, but this high appears to be associated with the Vatnajökull glacier rather than the ridge crest.

The $5^{\circ} \times 5^{\circ}$ average anomalies (Figure 2), as is expected, suppress most of the short-wavelength anomalies in the $1^{\circ} \times$ $1^{\circ}$ anomaly map. The boundary at $30^{\circ} \mathrm{N}$ is clearly expressed in the $5^{\circ} \times 5^{\circ}$ average gravity field. The $0-, 10-$, and $20-\mathrm{mGal}$ contours to the east of the ridge crest trend perpendicular to the ridge at that latitude, as do the -10 - and $-20-\mathrm{mGal}$ contours to the west of the ridge crest. The offset of the gravity contours at $30^{\circ} \mathrm{N}$ on the east side of the ridge crest is also seen in the $5^{\circ} \times 5^{\circ}$ average topographic contours (Figure 2). Another important feature of the $5^{\circ} \times 5^{\circ}$ average free air gravity anomaly map is intermediate-wavelength (1000-2000 km) gravity highs surrounding areas of unusual elevation. Many of these, such as Bermuda, the Cape Verde Islands, the Canary Islands, and Madeira, have been locations of extensive volcanic activity away from the midocean ridge system.

\section{Residual Gravity aNd DePTh ANOMALIES}

Cochran and Talwani [1977] examined surface ship gravity anomalies over midocean ridges in all of the world's oceans and found that they consistently show midocean crests to be associated with a relative maximum in the free air gravity field which they were able to quantify in terms of an empirical $1^{\circ} \times$ $1^{\circ}$ average gravity-age relationship (Figure 3). They found that the $1^{\circ} \times 1^{\circ}$ average free air gravity anomalies resulting from current thermal models of the lithosphere [Sclater and Francheteau, 1970; Lambeck, 1972; Parker and Oldenberg, 1973] are generally compatible with the observed gravity anomalies, although the thermal models predict a greater spreading rate dependence than is observed. Cochran and Talwani [1977] found a second-order spreading rate dependence of the $1^{\circ} \times 1^{\circ}$ average gravity anomalies associated with the midocean ridge system such that very fast spreading ridges are associated with a roughly $20-\mathrm{mGal}$ gravity high at the ridge crest, while very slow spreading ridges such as those in the North Atlantic are associated with a $25-$ to $30-\mathrm{mGal}$ high. The observed difference between fast and slow spreading ridges is much less away from the ridge crest. Cochran and Talwani [1977] concluded that the observed gravity anomalies could be adequately described by a curve in which only the primary dependence on age is considered and that it is more useful to establish a standard relationship for all oceans and discuss second-order variations between oceans than to establish a separate curve for each ocean. In addition to the gravity high over the ridge crest, compensated models of midocean ridges 


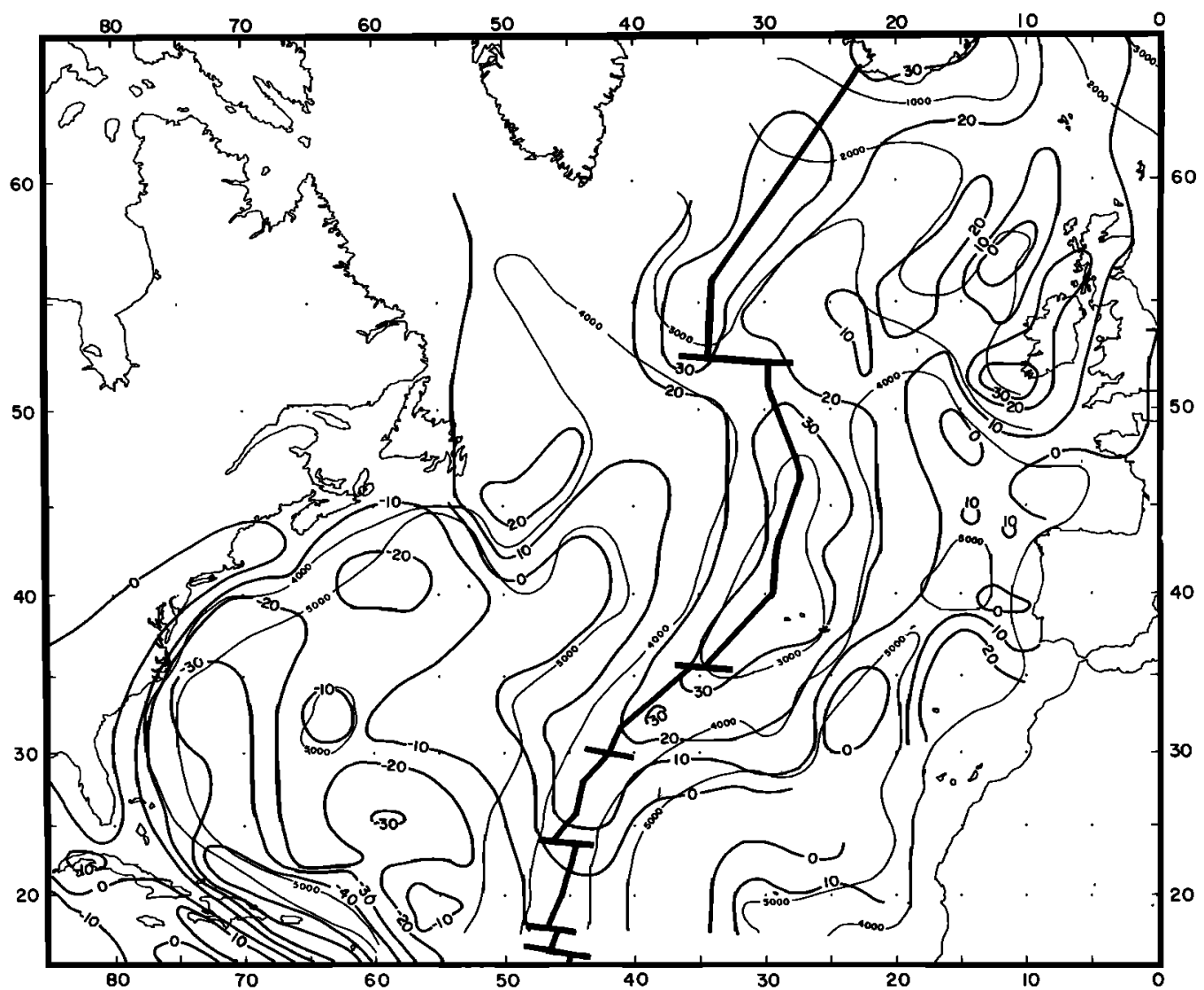

Fig. 2a. Map of $5^{\circ} \times 5^{\circ}$ free air gravity anomalies and depths in the North Atlantic. Gravity anomalies are contoured at 10 -mGal intervals, and depths at 1000 -m intervals. Gravity anomalies are referred to the hydrostatic figure of the earth (flattening $=1 / 299.7$ ). Anomalies north of $60^{\circ} \mathrm{N}$ are $5^{\circ} \times 10^{\circ}$ averages.

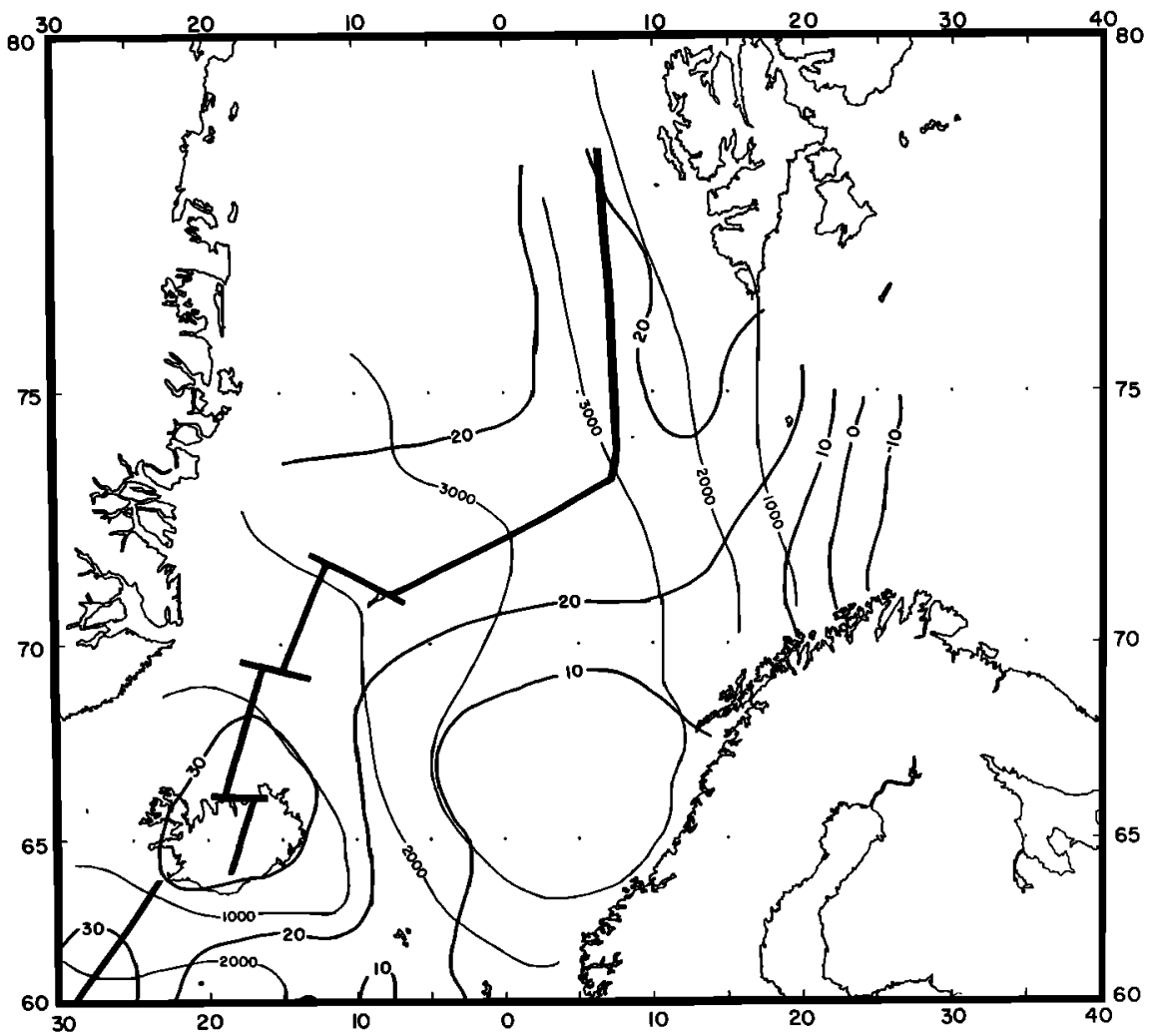

Fig. $2 b$. Map of $5^{\circ} \times 10^{\circ}$ free air gravity anomalies and depths in the Norwegian-Greenland Sea. Gravity anomalies are contoured at $10-\mathrm{mGal}$ intervals, and depths at $1000-\mathrm{m}$ intervals. Gravity anomalies are referred to the hydrostatic figure of the earth (flattening $=1 / 299.7$ ). 
produce broad bands of slightly negative anomalies (see Figure 6). These small negative anomalies are difficult to separate from the background field and are not included in the empirical curve for the sake of simplicity.

The empirical gravity-age relationship determined by Cochran and Talwani [1977] appears to be the result of the ridge and its compensation and is related to the evolution of the oceanic lithosphere. It is therefore reasonable to remove it from the observed $1^{\circ} \times 1^{\circ}$ free air gravity anomalies to allow the residual anomalies due to other causes to be examined.

We obtained $1^{\circ} \times 1^{\circ}$ average residual gravity anomalies in the North Atlantic Ocean by assigning an age to each $1^{\circ} \times 1^{\circ}$ square from the magnetic isochron maps of Pitman and Talwani [1972] using the Cenozoic time scale of Heirtzler et al. [1968] and then subtracting the $1^{\circ} \times 1^{\circ}$ average gravity anomaly appropriate to that age from the observed $1^{\circ} \times 1^{\circ}$ average free air anomalies. For areas older than $\mathbf{4 0}$ m.y. the empirical gravity curve for the ridge is zero, and therefore the residual gravity anomaly equals the free air anomaly. The $1^{\circ} \times 1^{\circ}$ residual gravity anomalies were summed and averaged to form $5^{\circ} \times 5^{\circ}$ average residual anomalies which are shown in Figure 4.

Residual depth anomalies were prepared in the same manner as were the residual gravity anomalies and are referred to the depth-age curve shown in Figure 3b. Ages were determined for the older portions of the North Atlantic from the magnetic isochron maps of Larson and Pitman [1972] by using the Mesozoic time scale of Larson and Hilde [1975]. The sign convention used is that shallow areas have positive depth anomalies. The observed $1^{\circ} \times 1^{\circ}$ average depths were obtained from bathymetric maps of Uchupi [1971]. Corrected basement depths were obtained by adding half of the $1^{\circ} \times 1^{\circ}$ average sediment thickness to the water depth to allow for the effect of sediment loading. This is equivalent to assuming local compensation and a density of $2.2 \mathrm{~g} / \mathrm{cm}^{3}$ for the sediment. Sediment thicknesses were determined from the isopach map of Ewing et al. [1973].

The nature of the $5^{\circ} \times 5^{\circ}$ average residual depth and gravity anomalies in the North Atlantic and their relationship to each other can be seen in Figure 5, which presents a series of west to east profiles at roughly $5^{\circ}$ spacings from $25^{\circ}$ to $55^{\circ} \mathrm{N}$ (profiles $a-g$ ) and a profile along the Mid-Atlantic Ridge crest (profile h).

The southernmost profile at $24.5^{\circ} \mathrm{N}$ (profile $a$ ) is south of the $30^{\circ} \mathrm{N}$ boundary and is characterized by depth anomalies that are from a few hundred meters positive to a few hundred meters negative except near the African continental margin at the extreme eastern end of the profile. The residual gravity anomalies are also near zero to the east of the ridge crest but fall off rapidly to the west $45^{\circ} \mathrm{W}$, a condition illustrating the

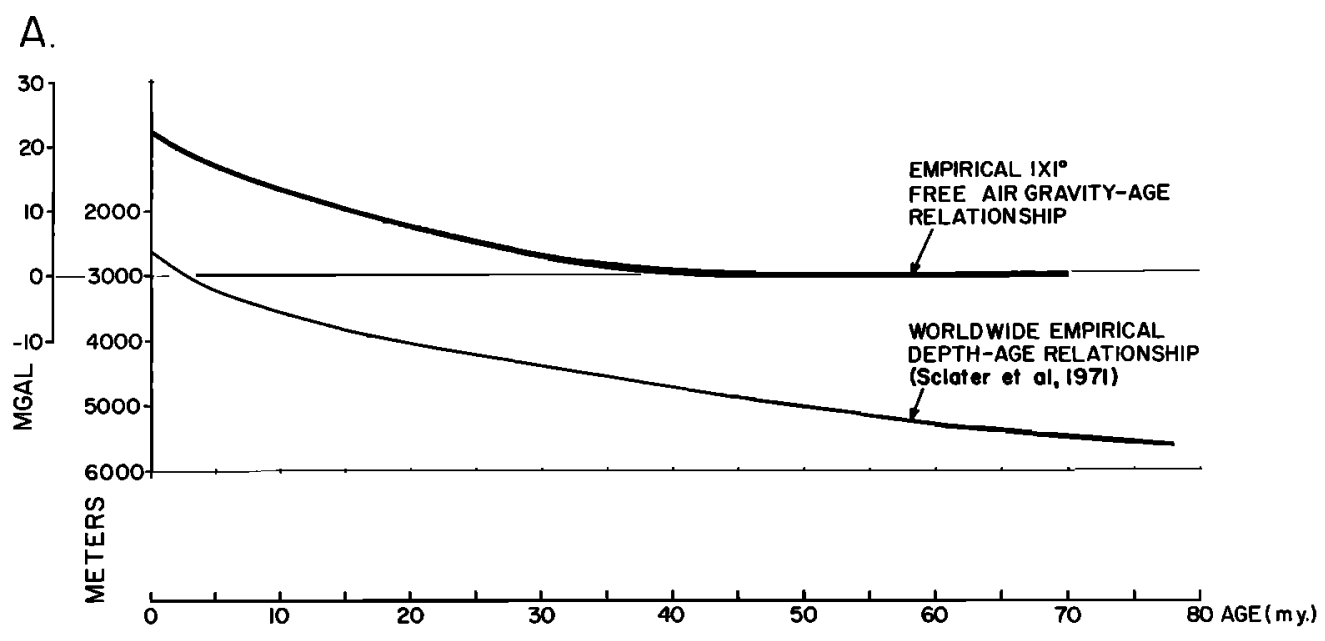

B.

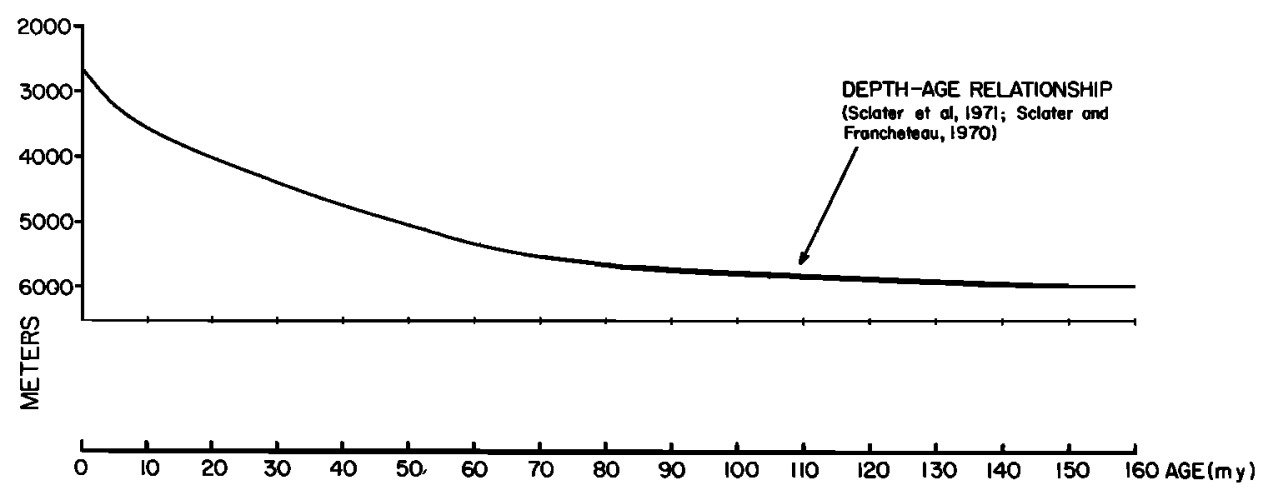

Fig. 3. (a) Empirical $1^{\circ} \times 1^{\circ}$ average free air gravity-age relationship after Cochran and Talwani [1977], which was developed through a comparison of gravity-age relationships in all of the oceans. There is some evidence of a small secondorder spreading rate dependence with fast spreading ridges slightly below and slow spreading ridges slightly above the curve. An empirical depth-age curve from Sclater et al. [1971] is shown for comparison. (b) Depth-age relationship used in calculating depth anomalies. For ages of less than $80 \mathrm{~m} . \mathrm{y}$. the curve is an empirical curve determined from data given by Sclater et al. [1971]. The older portion of the curve is obtained from the Sclater and Francheteau [1970] theoretical relationship. 


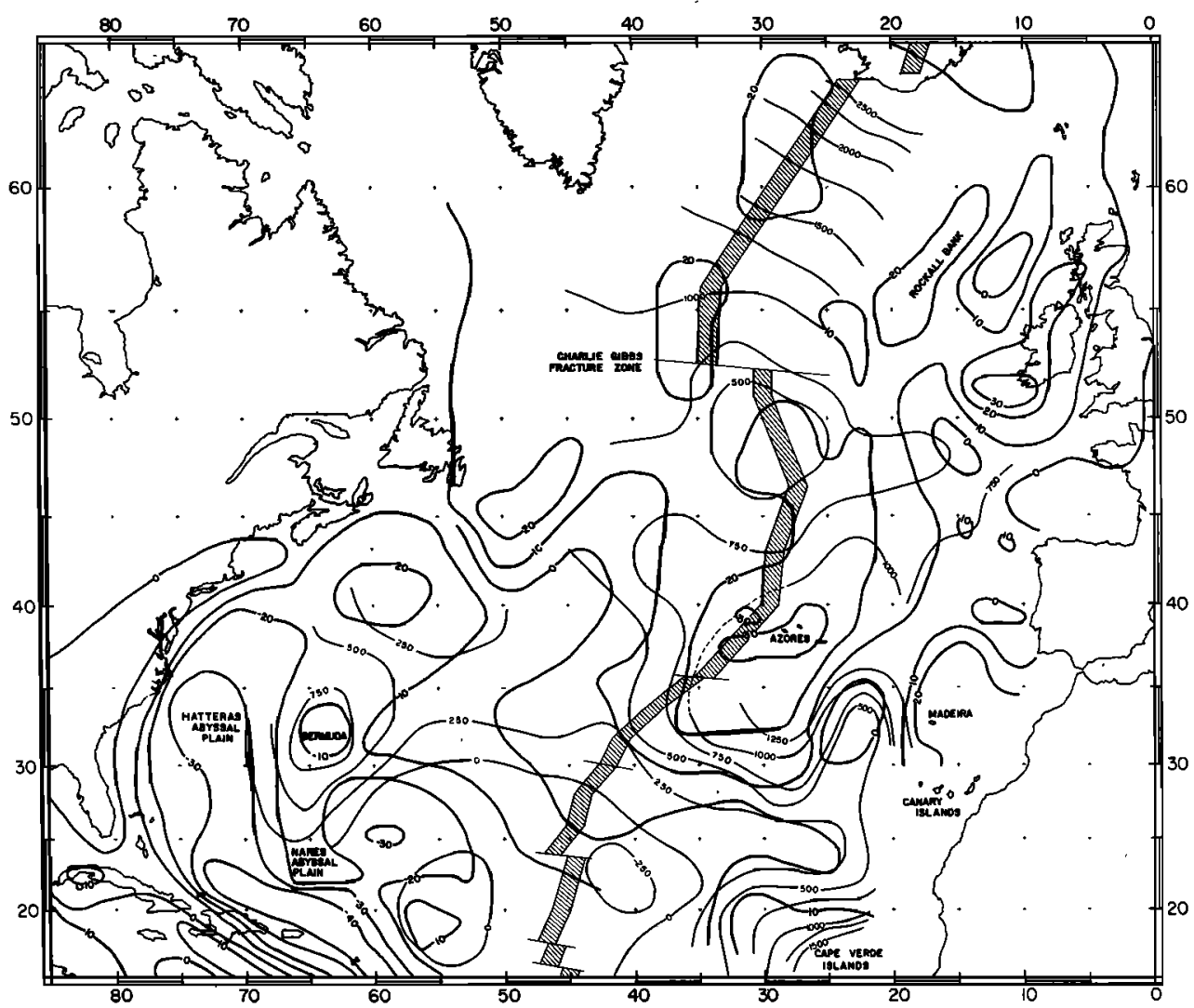

Fig. 4a. Map of $5^{\circ} \times 5^{\circ}$ residual gravity and depth anomalies in the North Atlantic [after Cochran and Talwani, 1977]. The gravity is contoured at $10-\mathrm{mGal}$ intervals, and the depth at $250-\mathrm{m}$ intervals. Values north of $60^{\circ}$ are $5^{\circ} \times 10^{\circ}$ averages.

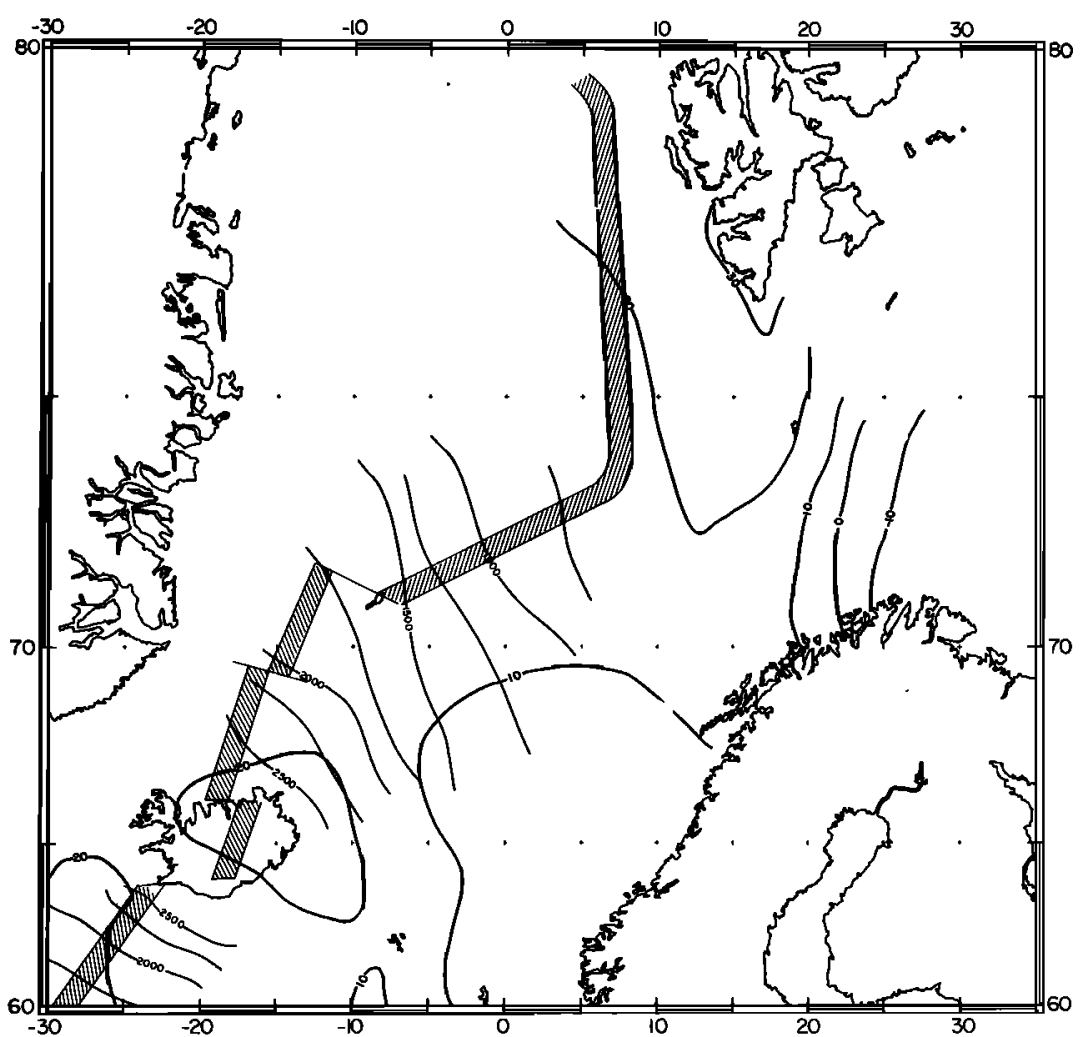

Fig. 4b. Map of $5^{\circ} \times 10^{\circ}$ residual gravity and depth anomalies in the Norwegian-Greenland Sea [after Cochran and Talwani, 1977]. The gravity is contoured at $10-\mathrm{mGal}$ intervals, and the depth at $250-\mathrm{m}$ intervals. 
pronounced asymmetry in the gravity field. The residual gravity and topographic highs located near $65^{\circ} \mathrm{W}$ are related to the southern extension of the Bermuda Rise.

The residual gravity anomalies at $30.5^{\circ} \mathrm{N}$ (profile $b$ ) show a pattern similar to those at $24.5^{\circ} \mathrm{N}$ (profile $a$ ), but the general level of the anomalies to the east of Bermuda is roughly 10 $\mathrm{mGal}$ higher. There are, however, some significant differences
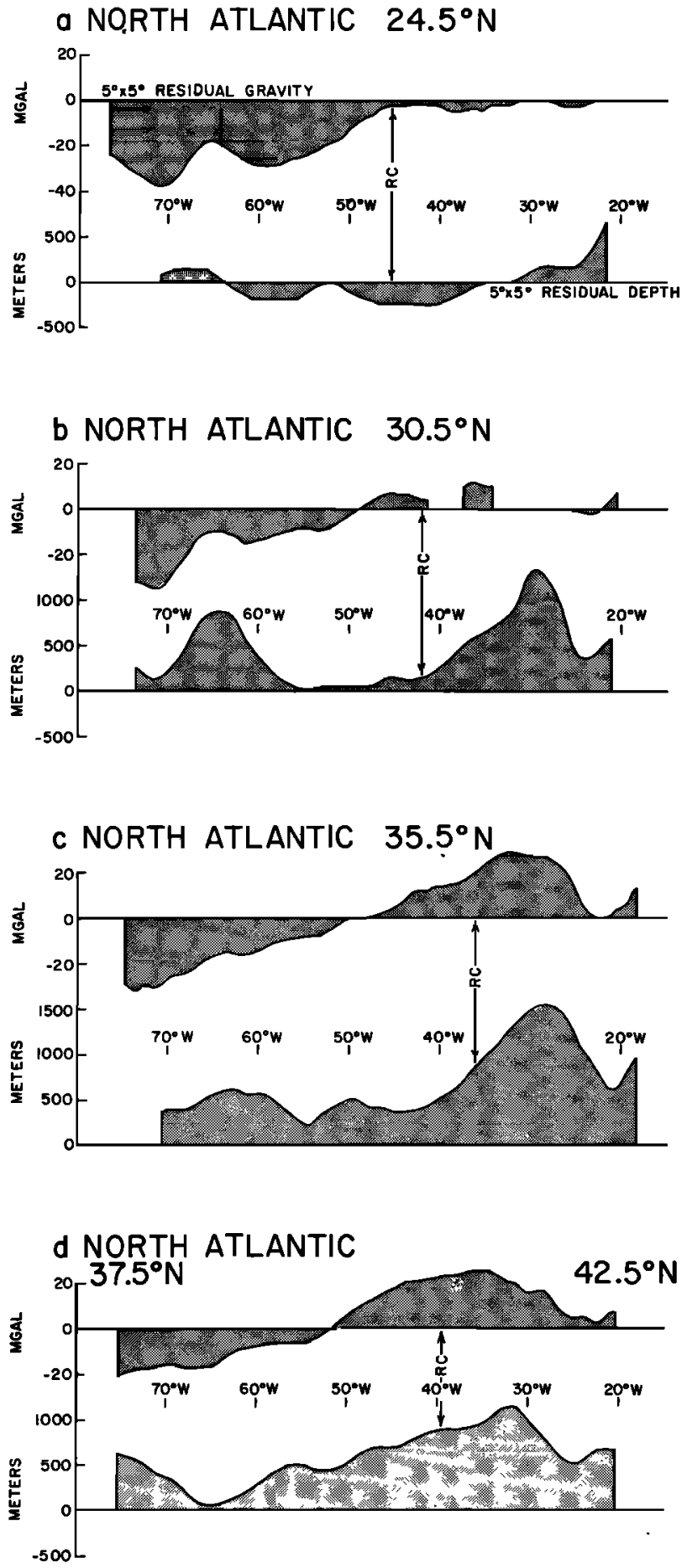

between profiles $a$ and $b$ in the depth anomaly pattern. First, since profile $b$ passes just south of Bermuda, the Bermuda Rise is much more prominent in the residual depth profile and is characterized by $5^{\circ} \times 5^{\circ}$ average depths nearly $1000 \mathrm{~m}$ shallower than those predicted. Second, the eastern flank of the Mid-Atlantic Ridge is unusually high between the ridge crest and the line of seamounts extending south from the Azores. As
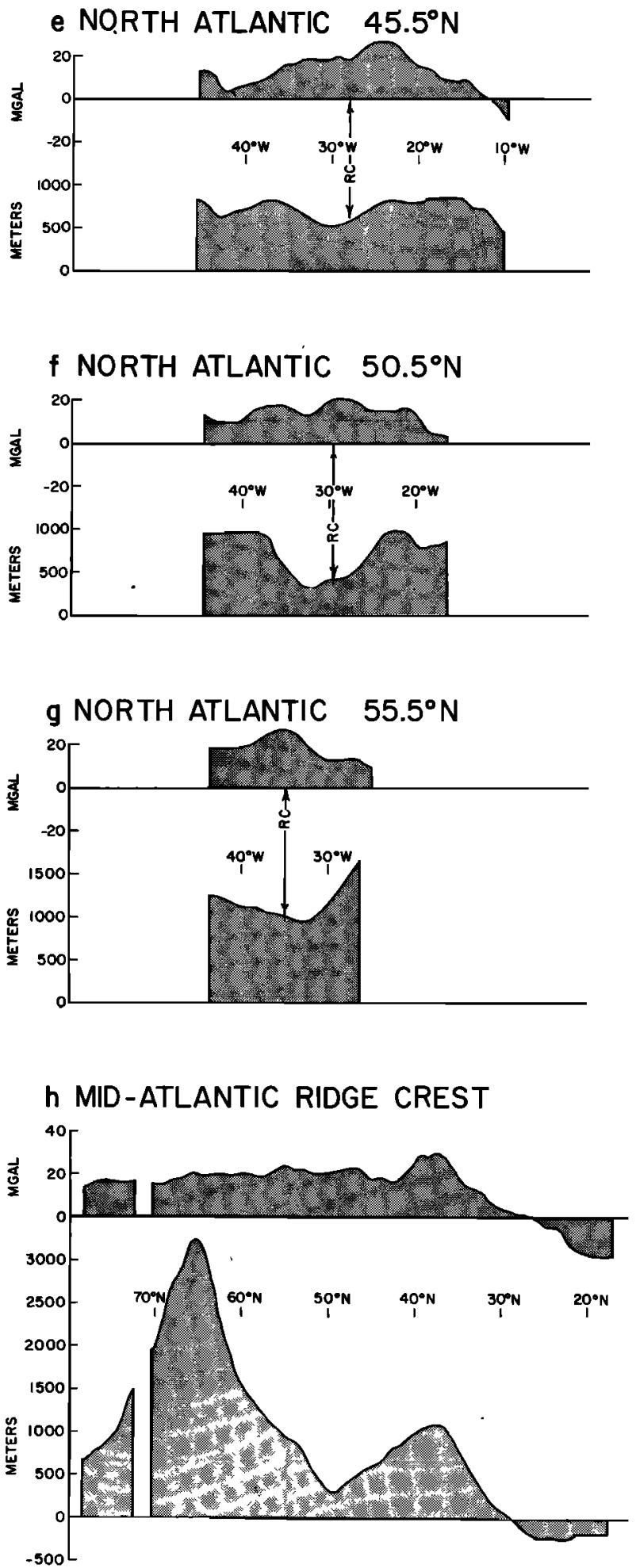

Fig. 5. Profiles of $5^{\circ} \times 5^{\circ}$ average residual gravity and depth anomalies in the North Atlantic. Profiles $a-g$ run west to east across the Mid-Atlantic Ridge at roughly $5^{\circ}$ spacings. Profile $h$ runs along the crest of the Mid-Atlantic Ridge. The points at which profiles cross the ridge crest are marked by ' $R C$ '. 
a result, the depth anomalies increase steadily from about 250 $\mathrm{m}$ at the ridge crest to between 1000 and $1500 \mathrm{~m}$ near $30^{\circ} \mathrm{W}$. Gravity data are somewhat sparse east of the ridge crest, but the available data indicate $5^{\circ} \times 5^{\circ}$ average residual anomalies of slightly more than $10 \mathrm{mGal}$ at this latitude over the plateau between the ridge crest and the seamount chain. The gravity anomalies appear to follow the topography in dropping off rapidly east of $30^{\circ} \mathrm{W}$ before increasing again toward Madeira. The two profiles flanking the Azores (profiles $c$ and $d$ ) are characterized by broad highs in both the residual gravity and the depth anomalies centered to the east of the ridge crest. The depth anomaly high is sharper in profile $c$ at $35.5^{\circ} \mathrm{N}$ and reflects the presence of the Azores Platform. The high is broader in profile $d$, and although it is centered east of the ridge crest, it extends well to the west. Gravity and depth anomalies fall off both east and west of the Azores, so there is a correlation between the two parameters in that region. The depth anomalies level off at a value of about $500 \mathrm{~m}$ near $45^{\circ} \mathrm{W}$ and are relatively constant west of that longitude, while the gravity anomalies continue to decrease to the west. The depth anomaly minimum near $65^{\circ} \mathrm{W}$ on profile $d$ is over an area of thick and variable sediments to the west of the Newfoundland Ridge [Ewing et al., 1973] and may be in part the result of uncertainties in accounting for the sediment loading.

North of about $45^{\circ} \mathrm{N}$ the $5^{\circ} \times 5^{\circ}$ average residual gravity anomalies still take the form of a broad arch centered near the ridge crest, but it is a much flatter high and occupies most of the ocean (profile $e$ ), which is younger and thus narrower than that to the south of the Azores. The large negative gravity anomalies in the western basin are confined to the older portion of the Atlantic south of the Grand Banks.

The $5^{\circ} \times 5^{\circ}$ average depth anomaly contours on the Reykjanes Ridge are nearly perpendicular to the ridge crest (see Figure 4), and the values increase rapidly toward Iceland. Just south of the Charlie Gibbs fracture zone, a prominent depth anomaly minimum is centered near the ridge crest (Figure 4). Neither this feature nor the rapid increase in the depth anomalies toward Iceland on the Reykjanes Ridge is reflected in the residual gravity anomalies which maintain values of about $20 \mathrm{mGal}$ from $40^{\circ}$ to $70^{\circ} \mathrm{N}$ (profile $h$, Figure 5).

The residual gravity anomalies in the North Atlantic are thus dominated by two features. The first is a broad gravity high which occupies the central portion of the ocean from $30^{\circ} \mathrm{N}$ to the Azores and most of the North Atlantic north of the Azores. South of the Azores it is centered just to the east of the Mid-Atlantic Ridge over a large topographic high. North of the Azores there is generally not a direct correspondence between variations in the gravity and the depth anomalies (as is shown particularly in profiles $f$ and $h$, Figure 5), although both are consistently positive over the same regions.

The other feature is a large area of negative anomalies in the western basin, which follows the western margin of the ocean from about $40^{\circ} \mathrm{N}$ into the South Atlantic. This feature has no relationship to the residual depth anomalies except that it is interrupted by an intermediate-wavelength gravity and topographic high over the Bermuda $R$ ise.

\section{North Atlantic Gravity Field Models}

In this section we wish to quantitatively investigate the pattern of gravity and depth anomalies in the North Atlantic Ocean. Specifically, we will concentrate on the area north of $30^{\circ} \mathrm{N}$ in which unusually shallow depths and large positive gravity anomalies are found over the same region. We will begin by determining the gravity anomalies resulting from a 'model' midocean ridge and its compensation on a spherical earth and then will examine how the $1^{\circ} \times 1^{\circ}$ residual depth anomalies in the North Atlantic can be compensated in order to minimize the residual gravity anomalies. Finally, the implications and possible origin of the gravity and depth anomalies will be discussed.

It should be noted that our models are all compensated in that we seek to determine a family of mass distributions which can explain the observed gravity anomalies with the assumption that the pressure at some depth is a constant. There are thus two limitations on the model studies which follow. The first is that they are static models concerned with the distribution of mass and do not explicitly include any dynamic effects, although it is possible to invoke dynamic processes to produce and maintain the inferred mass distribution. The second limitation is that our models assume that any processes which are at work are isostatic in the sense that they produce a compensated mass distribution. An uncompensated uplift (or depression) of the lithosphere will produce a gravity effect which can be approximated by that of a Bouguer slab, $\Delta g=$ $2 \pi G \Delta \rho \Delta h$, where $\Delta h$ is the amount of uplift and $\Delta \rho$ is the density contrast between asthenosphere and water. Thus the gravity effect of simply uplifting the lithosphere by $1 \mathrm{~km}$ is about $95 \mathrm{mGal}$. The residual gravity anomalies of $15-20 \mathrm{mGal}$ observed in the North Atlantic could thus result from only 150 to about $200 \mathrm{~m}$ of uncompensated uplift. The observed depth anomalies in the region north of the $30^{\circ} \mathrm{N}$ boundary are much greater than that, averaging about $1 \mathrm{~km}$. It can thus be concluded that the mass excess associated with the unusually shallow depths in the North Atlantic is at least in part balanced by a mass deficiency somewhere which greatly reduces the gravity effect of the excess elevation. For the purposes of carrying out our calculations we will assume that the compensation is exact, that is, that the excess is exactly balanced by the deficiency.

The input data for the spherical earth model calculations are averages over $1^{\circ} \times 1^{\circ}$ squares of depth, sediment thickness, and lithospheric age. As a result, we can describe the structure in terms of $1^{\circ} \times 1^{\circ}$ prisms and calculate the gravity effect of each prism by using an expression for the gravity effect of a radial mass line. The details of the gravity model calculations are given in the appendix.

Figure 6 shows the $1^{\circ} \times 1^{\circ}$ average free air anomalies calculated for a model Mid-Atlantic Ridge. The depths for the model ridge are given by the depth-age relationship in Figure 3b. Continental areas such as Rockall Plateau are assumed to be at their actual depth. The compensation of the ridge is assumed to occur by a density inversion of constant magnitude in the asthenosphere immediately beneath the lithosphere. For the calculations shown in Figure 6 we assumed that the compensation occurs above a depth of $100 \mathrm{~km}$ and has a density contrast of $-0.085 \mathrm{~g} / \mathrm{cm}^{3}$ with the lithosphere. The model is illustrated in Figure $7 a$. This is the method of compensation assumed by Parker and Oldenberg [1973] in calculating their theoretical ridge heights, and the top of the compensating body differs only slightly from their lithosphere-asthenosphere boundary because they chose a slightly different density contrast $\left(-0.082 \mathrm{~g} / \mathrm{cm}^{3}\right)$. Thus the gravity anomaly pattern shown in Figure 6 is that of a midocean ridge with the lithospheric ages and boundaries of the North Atlantic but at the depths predicted by the curve in Figure $3 b$ and where the lithosphere evolves according to a simple Parker-Oldenberg thermal model.

The main feature of Figure 6 is a gravity high of $25-35 \mathrm{mGal}$ 


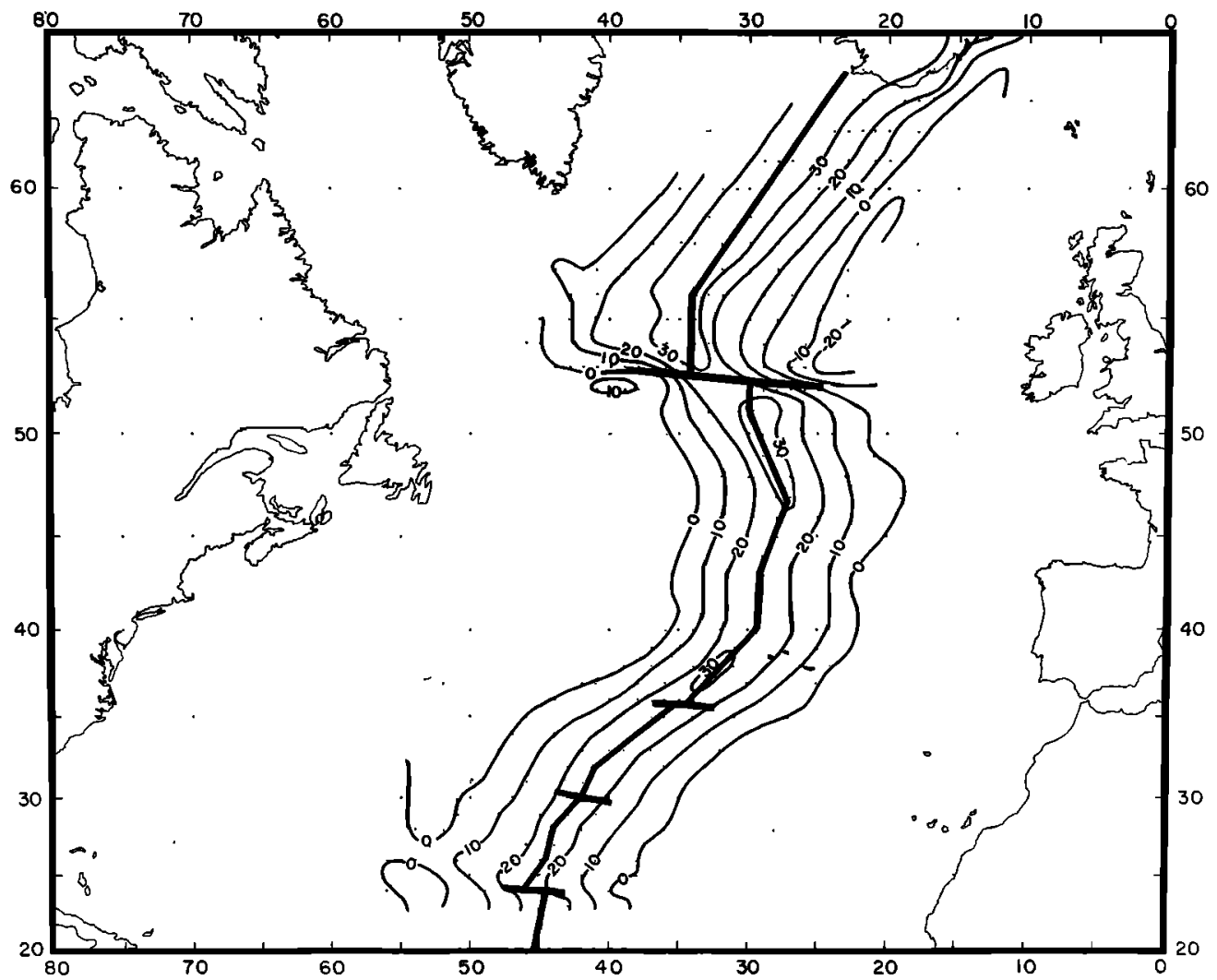

Fig. 6. Calculated $1^{\circ} \times 1^{\circ}$ free air gravity anomalies obtained for a three-dimensional spherical earth model of a midocean ridge which has the geometry of the North Atlantic but which has depths predicted by the depth-age curve of Figure $3 b$ rather than the observed depths. Compensation of the ridge is assumed to occur by a density inversion of constant magnitude in the asthenosphere above a depth of $100 \mathrm{~km}$ (Figure $7 a$ ). The calculated $1^{\circ} \times 1^{\circ}$ average anomalies are similar to, but 5-10 mGal higher than, the empirical gravity-age curve shown in Figure $3 a$.

over the ridge crest, which falls off to zero near the 50 -m.y. isochron and is flanked by broad areas of slightly negative anomalies. Beyond these the values return to zero. The calculated ridge crest high is similar to the gravity high of 25-30 mGal observed over slow spreading ridges [Cochran and Talwani, 1977].

Since the gravity anomaly pattern in Figure 6 is quite similar to that observed by Cochran and Talwani [1977], the model of compensation illustrated in Figure $7 a$ was incorporated into all of the models discussed below to compensate the basic subsidence away from the ridge crest.

A simple model for the unusually shallow depths in the North Atlantic is that they are due to increased temperatures in the asthenosphere immediately below the lithosphere, a situation leading to thermal expansion and lowered densities in the upper portion of the asthenosphere. Such a model is shown schematically in Figure $7 b$. This model is suggested by the presence of large seismic $\boldsymbol{P}$ wave arrival time residuals beneath Iceland [Trygguason, 1964; Long and Mitchell. 1970] and by studies of $S c S$ travel time residuals that indicate that shear wave velocities are anomalously low in the mantle directly beneath oceanic islands, including Iceland [Sipkin and Jordan, 1975; Okal and Anderson, 1975]. It is also a model which has been used to approximate a situation in which elevation anomalies are ascribed to convection in the asthenosphere beneath the lithospheric plate (see, for example, Watts [1976]).

Figure 8 shows the $1^{\circ} \times 1^{\circ}$ average free air gravity anomalies calculated for the North Atlantic by using a model such as is pictured in Figure $7 b$. In the calculations we assumed that the elevation anomalies are compensated by a low-density body in the upper portion of the asthenosphere. The top of the body coincides with the base of the lithosphere and has a density contrast of $-0.085 \mathrm{~g} / \mathrm{cm}^{3}$ with normal asthenosphere. This model results in gravity anomalies which closely reflect the depth anomalies. Large $1^{\circ} \times 1^{\circ}$ average free air gravity highs are found over the Azores (101 $\mathrm{mGal}$ ) and Iceland (126 $\mathrm{mGal}$ ), and the deep compensation of the two topographic highs is seen over wide areas depressing the gravity field in surrounding areas. As a result, the calculated gravity anomalies near the ridge crest just south of the Charlie Gibbs fracture zone are about $15 \mathrm{mGal}$, which is only half of the anomalies calculated for the model ridge and much less than the 40- to 50 -mGal $1^{\circ} \times 1^{\circ}$ average gravity anomalies observed in that region.

An entirely different model is illustrated in Figure $7 c$. Here we have assumed that the depth anomalies are compensated at shallow depths within the lithosphere, in this case by variations in crustal thickness. The free air gravity anomalies resulting from the application of this model to the North Atlantic are shown in Figure 9. Because of the very shallow compensation the depth anomalies make only a very small contribution, and this model results in free air anomalies which are quite similar to those for the model ridge (Figure 6). The main difference is that the ridge crest high broadens out near Iceland and the Azores to include the area of largest depth anomalies. In general, though, the anomalies are within a few milligals of those calculated for the model ridge. As a result, most of the Atlantic from $30^{\circ}$ to $60^{\circ} \mathrm{N}$ is characterized by calculated $1^{\circ} X$ $1^{\circ}$ average gravity anomalies significantly less than those observed.

These two models illustrate the difficulties encountered in 

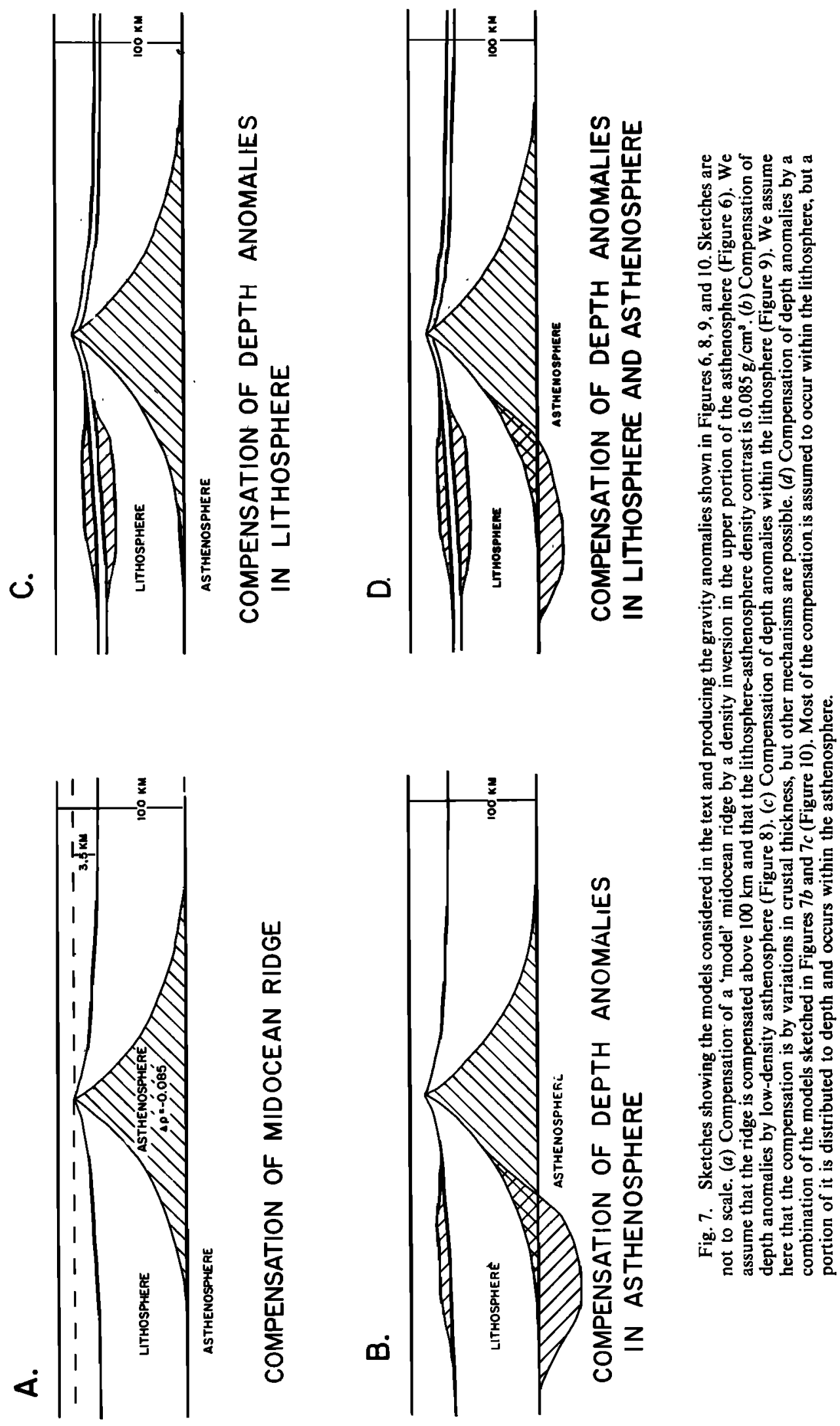

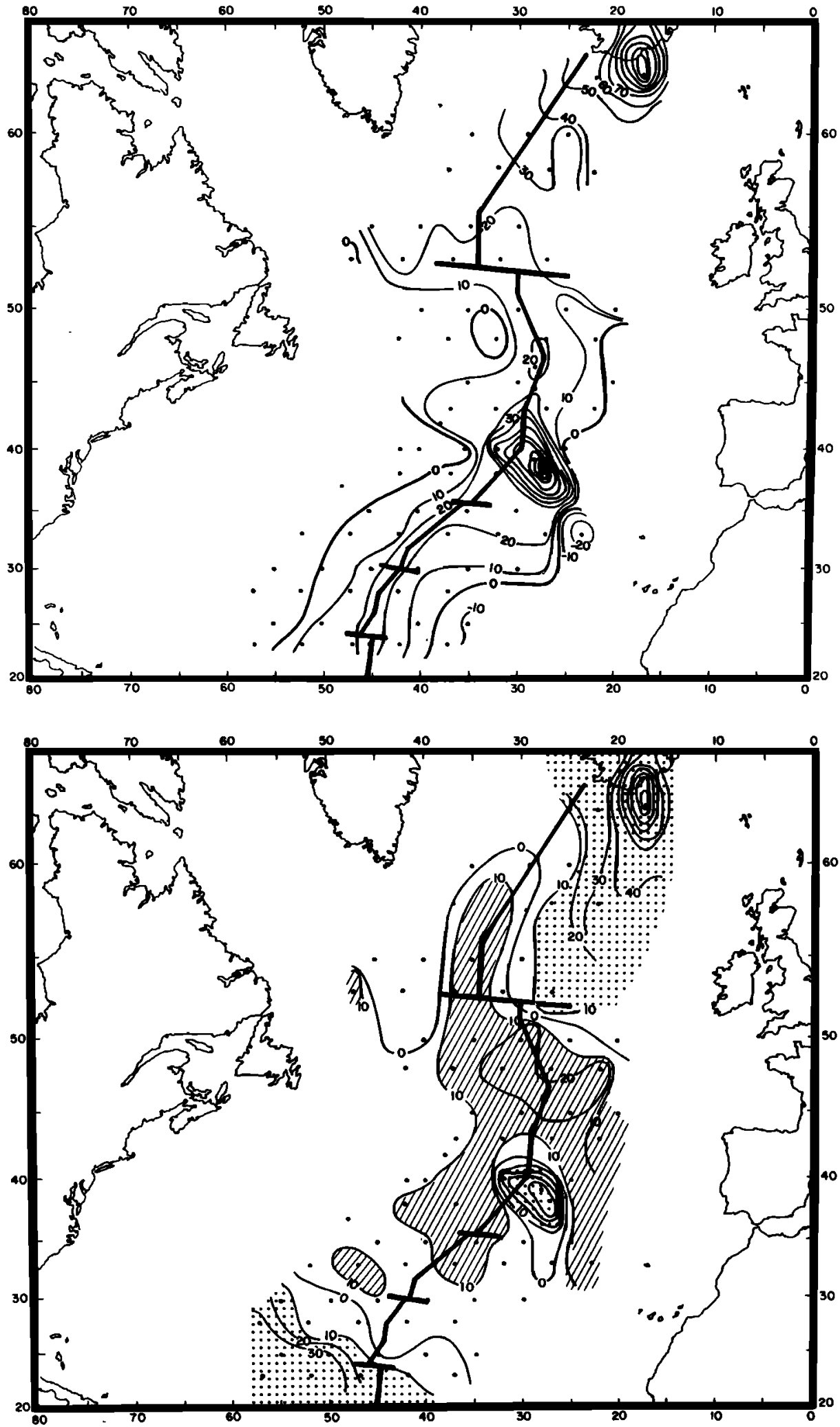

Fig. 8. Map of $1^{\circ} \times 1^{\circ}$ average gravity anomalies obtained for a model in which the predicted Mid-Atlantic Ridge is compensated as in Figure 6 and the residual elevation is compensated by a low-density body in the asthenosphere immediately beneath the lithosphere (Figure $7 b$ ). The upper map shows the calculated $1^{\circ} \times 1^{\circ}$ free air anomalies, and the lower map the difference between calculated and observed anomalies. Areas in which the calculated anomalies are more than $10 \mathrm{mGal}$ too high are stippled; areas in which they are more than $10 \mathrm{mGal}$ too low are ruled. Dots show locations at which anomalies were calculated. 

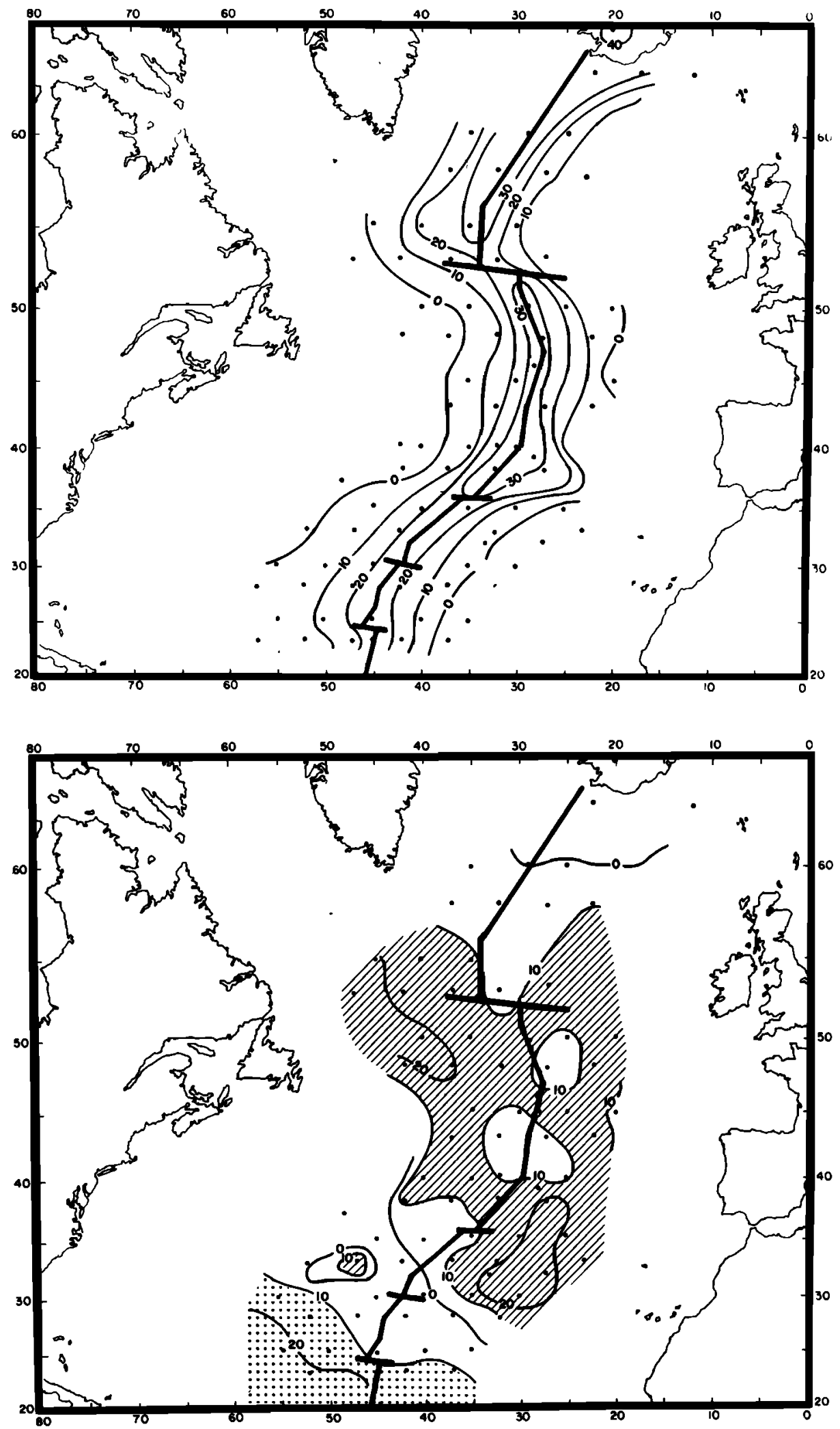

Fig. 9. Map of $1^{\circ} \times 1^{\circ}$ average gravity anomalies obtained for a model in which the predicted Mid-Atlantic Ridge is compensated as in Figure 6 and the residual elevation is compensated by varying the crustal thickness (Figure 7c). The upper map shows the calculated $1^{\circ} \times 1^{\circ}$ free air anomalies, and the lower map the difference between calculated and observed anomalies. Areas in which the calculated anomalies are more than $10 \mathrm{mGal}$ too high are stippled: areas in which they are more than $10 \mathrm{mGal}$ too low are ruled. Dots show the locations at which anomalies were calculated. Note the similarity of calculated anomalies to those in Figure 6. 
attempting to reproduce the observed gravity anomalies by compensation of the depth anomalies with a single simple body. If the compensation is deep, it results in large gravity highs over the Azores and Iceland rather than the nearly flat gravity field which is observed on profiles along isochrons (profile $h$, Figure 5). If the compensation is brought shallow enough that the gravity values are relatively constant along isochrons, then the model does not duplicate the other major characteristic of the North Atlantic gravity field, which is that north of $30^{\circ} \mathrm{N}$ the general level of the gravity anomalies is $15-20 \mathrm{mGal}$ greater than that observed over other midocean ridges or predicted by ridge models.

A satisfactory model can be obtained by assuming that most of the compensation occurs at shallow depths but that a portion of it is distributed to greater depths. The free air gravity anomaly pattern resulting from one such model is shown in Figure 10. For this particular model, illustrated in Figure 7d, we have assumed that in the anomalous portion of the North Atlantic, that is, east of $40^{\circ} \mathrm{W}$ from $30^{\circ}$ to $40^{\circ} \mathrm{N}$ and in the entire width of the ocean north of $40^{\circ} \mathrm{N}$, there is a low-density body in the upper portion of the asthenosphere which is capable of compensating $500 \mathrm{~m}$ of excess elevation. The difference between $500 \mathrm{~m}$ of excess elevation and the observed depth anomalies were assumed to be compensated at shallow depths through variations in crustal thickness, as were all depth anomalies outside of the unusual area. We assumed a density contrast of $-0.006 \mathrm{~g} / \mathrm{cm}^{3}$ for the anomalous asthenosphere, which implies a thickness of $200 \mathrm{~km}$ for the compensating body or that compensation is distributed to a depth of about $300 \mathrm{~km}$.

The areas of significant residual gravity anomalies are greatly reduced in Figure 10 in comparison with those in Figures 8 and 9 . It should be pointed out that the model illustrated in Figure 10 does not represent an attempt to find a 'best fitting' model or set of parameters. It is rather an example of one of a family of solutions which reproduce the general characteristics of the observed gravity field in which we have adopted convenient values for the various variables. Common characteristics of acceptable solutions are that most of the compensation of the depth anomalies occurs within the lithosphere but that within the anomalous region north of the $30^{\circ} \mathrm{N}$ boundary a portion of the compensation must extend to a depth of several hundred kilometers. Also, the deep mass deficiency must be of a nearly uniform amount throughout the anomalous area. The mainly shallow compensation is necessary in order that the gravity field be relatively uniform along isochrons and not reflect the large variations in depth. The deep compensation of a portion of the depth anomalies is necessary to elevate the general level of the field by 15-20 $\mathrm{mGal}$ above the anomaly due to the midocean ridge. The implication is that the Iceland and Azores topographic highs are for the most part compensated at relatively shallow depths but that the overall elevation of the North Atlantic is maintained at some greater depth.

\section{Discussion}

The assumption of a particular mechanism of compensation, such as variations in crustal thickness, and the division of the compensation into a shallow body and a deep body are only mathematical conveniences. What is implied by the model studies is that the compensation of the regional depth anomalies in the North Atlantic must be distributed over several hundred kilometers and involve both the litho- sphere and the asthenosphere. Also, the deep contribution must be fairly uniform over the entire anomalous region.

We thus agree with Sclater et al. [1975] that the asthenosphere must be involved in maintaining the depth anomalies in the North Atlantic. However, we disagree with them in that we have found that the large long-wavelength depth anomalies in the North Atlantic cannot originate entirely within the asthenosphere and in that there is not a simple one to one direct relationship between gravity and depth anomalies passing through the origin such as they hypothesize. A direct relationship between gravity and depth anomalies apparently can exist over single isolated features such as the Hawaiian Swell, as was demonstrated by Watts [1976]. Even there though, the gravity anomalies associated with the Hawaiian Swell are superimposed on longer-wavelength gravity anomalies unassociated with the oceanic depth, so that zero depth anomalies are associated with gravity anomalies of -15 to $-20 \mathrm{mGal}$.

If the direct relationship hypothesized by Sclater et al. [1975] actually holds in the North Atlantic, then $5^{\circ} \times 5^{\circ}$ average gravity anomalies of more than $100 \mathrm{mGal}$ would be expected at Iceland, which is much larger than those observed (see Figure 2). A second example is the western basin of the North Atlantic. Large negative gravity anomalies are found over this region (see Figure 1), which has depths near or slightly shallower than those predicted for crust of that age. The correlation observed by Sclater et al. [1975] probably results from the fact that they had a limited data set which included data from the intermediate-wavelength topographic high surrounding Madeira, the Canary Islands, and the Cape Verde Islands as well as the transition from the North Atlantic Gravity High to more normal crust to the south and west of the Azores. They apparently did not use data from the western basin or from north of $50^{\circ} \mathrm{N}$.

As was mentioned above, the models which we have considered constitute a limited class of models which are compensated in the sense that we assume that an isobaric surface exists at some depth in the earth. We have not considered nonisostatic models or the stresses that will arise in either case.

In fact, deep compensation is achieved through the presence of lateral inhomogeneities in the asthenosphere, which implies the existence of nonhydrostatic stresses. An order of magnitude calculation of the stresses is given by $\Delta \rho h g$, where $\Delta \rho$ is the density contrast, $h$ the thickness of the anomalous region, and $g$ the gravity. For the model producing the anomalies shown in Figure 10 this gives an order of magnitude estimate of 120 bars. For the low upper asthenospheric viscosities which have been deduced from glacial rebound studies [Artyushkov, 1971; Walcott, 1973] such stresses will cause creep and must be supported in some manner if the anomalous region is to maintain its identity over a geologically significant time.

A simple model for the pattern of gravity and depth anomalies observed in the North Atlantic is that the mantle is unusually hot and that both lithosphere and asthenosphere are affected to a depth of several hundred kilometers. The temperature increase in the asthenosphere need not be very great. Using a coefficient of thermal expansion of $2 \times 10^{-5}$ ${ }^{\circ} \mathrm{C}^{-1}$ [McKenzie et al., 1974] and the density difference of $-0.006 \mathrm{~g} / \mathrm{cm}^{3}$ used in the model of Figure $7 c$ to produce the anomalies in Figure 10 gives an increase of temperature of about $75^{\circ} \mathrm{C}$.

McKenzie et al. [1974] concluded from the concentration of radioactive elements in oceanic basalts and the measured heat flow that roughly half of the heat released at the surface is 

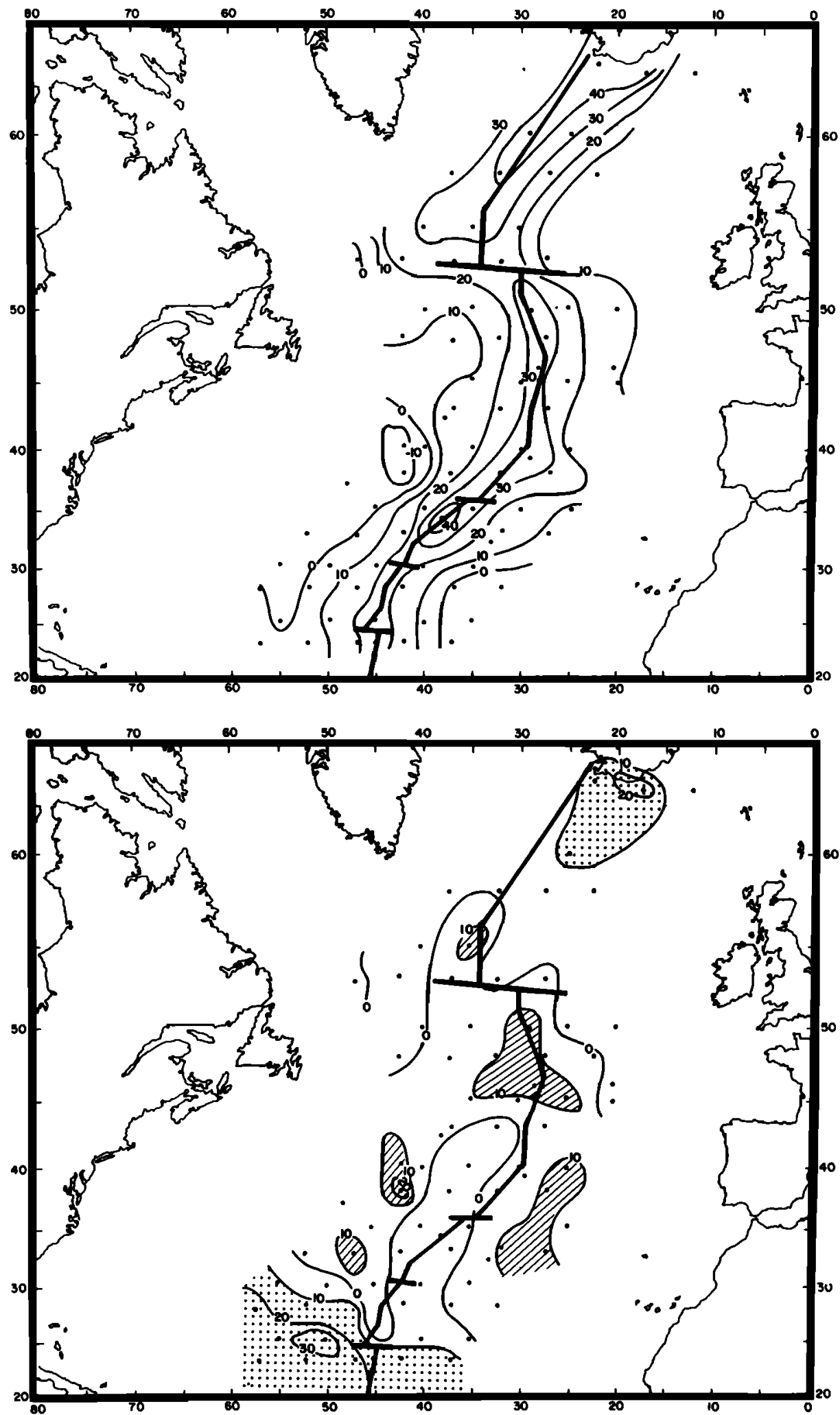

Fig. 10. Gravity anomalies obtained for a model in which the predicted Mid-Atlantic Ridge is compensated as in Figure 6 and the residual elevation is compensated by variations in crustal thickness except in a region north of $30^{\circ} \mathrm{N}$ and east of $40^{\circ} \mathrm{N}$ and in the entire ocean north of $40^{\circ} \mathrm{N}$. In these areas, $500 \mathrm{~m}$ of excess elevation are compensated by a low-density body in the asthenosphere immediately beneath the lithosphere, and the remainder by variations in crustal thickness (Figure $7 d$ ). The low-density body is assumed to have a density contrast of $-0.006 \mathrm{~g} / \mathrm{cm}^{\mathrm{a}}$ with the surrounding mantle and thus has a thickness of $200 \mathrm{~km}$. The upper map shows the calculated $1^{\circ} \times 1^{\circ}$ free air gravity anomalies, and the lower map the difference between calculated and observed anomalies. Areas in which the calculated anomalies are more than $10 \mathrm{mGal}$ too high are stippled; areas in which they are more than $10 \mathrm{mGal}$ too low are ruled. Dots show locations at which anomalies were calculated. 
from the upper mantle and half from the lower mantle. Recently, $O^{\prime}$ Nions et al. [1978], using revised values for the mean oceanic heat flow [Williams and Von Herzen, 1974] and for the concentrations of heat-producing elements, concluded that 'a significant amount of the heat lost by cooling of the oceanic lithosphere is generated in the lower mantle.' They also argued that their isotope data imply that heat transfer from the lower to the upper mantle does not appear to be accompanied by transport of the heat-producing elements to the surface, that is, by a deep mantle plume.

Whether heat transfer from the lower to the upper mantle occurs by conduction across a thermal boundary layer at 700 $\mathrm{km}$ as suggested by McKenzie and Weiss [1975], by upward migration of volatiles as suggested by the work of Wyllie [1971] and Green [1971], or by some other mechanism such as plumes, there is no reason to assume that this heat transfer is evenly distributed over the earth. Thus it is possible that the large area of lowered densities which we have deduced to exist beneath the North Atlantic results from an uneven transfer of heat from the lower to the upper mantle.

Langseth and Zielinski [1974] compiled and examined heat flow measurements in the Norwegian-Greenland Sea and on the flanks of the Reykjanes Ridge. They concluded that a large area of abnormally high heat flow extends from at least as far south as the Charlie Gibbs fracture zone to as far north as they had data (roughly $77^{\circ} \mathrm{N}$ ).

Our results also imply that the topographic highs surrounding Iceland and the Azores are compensated at fairly shallow depths, that is, within the lithosphere. Let us examine these results in the context of arguments made concerning the nature of areas such as Iceland and the Azores on the basis of geochemical data.

Schilling [1973] proposed on the basis of variations in rare earth and minor element concentrations that basalts erupted on Iceland have a distinctly different source than basalts erupted on the Mid-Atlantic Ridge away from the Iceland area. He demonstrated that concentrations of incompatible elements such as $\mathrm{K}, \mathrm{Ti}, \mathrm{P}$, and the light rare earths (as demonstrated by the ratio $\mathrm{La} / \mathrm{Sm}$ ) and the ratio $\sum \mathrm{FeO} / \sum \mathrm{FeO}+$ $\mathrm{MgO}$ increase systematically toward Iceland along the Reykjanes Ridge from about $60^{\circ} \mathrm{N}$. He interpreted these variations as resulting from the mixture of material from two sources, a 'primordial hot mantle plume' rising from deep beneath Iceland and the 'depleted low-velocity layer' found under the Mid-Atlantic Ridge. $\mathrm{Sr}$ and $\mathrm{Pb}$ isotope data were also cited as support for the existence of separate sources for the two areas.

The presence of a narrow, deep structure extending to the lower mantle and resembling a plume (Figures $11 a$ and $11 b$ ) beneath Iceland cannot be deduced from our data. However, it should be pointed out that such a structure would be difficult to detect from surface measurements in any event. What can be said from our data is that shallow compensation is present in the vicinity of Iceland, and therefore if a plume is present, it must serve as a conduit for bringing a large quantity of lowdensity material to the surface from deep in the mantle to produce the low-density lithosphere in the vicinity of Iceland.

On the other hand, we have also established the presence of a low-density area within the upper mantle beneath the North Atlantic over an area much larger than that of the geochemical and bathymetric anomalies associated with Iceland. This suggests the possibility that deep plumes may not be involved at all in the production of hot spots but that material from a depth of no more than 200 or $300 \mathrm{~km}$ can be invoked as the source of the extraordinary volcanic activity at Iceland and the Azores as sketched in Figure $11 c$.

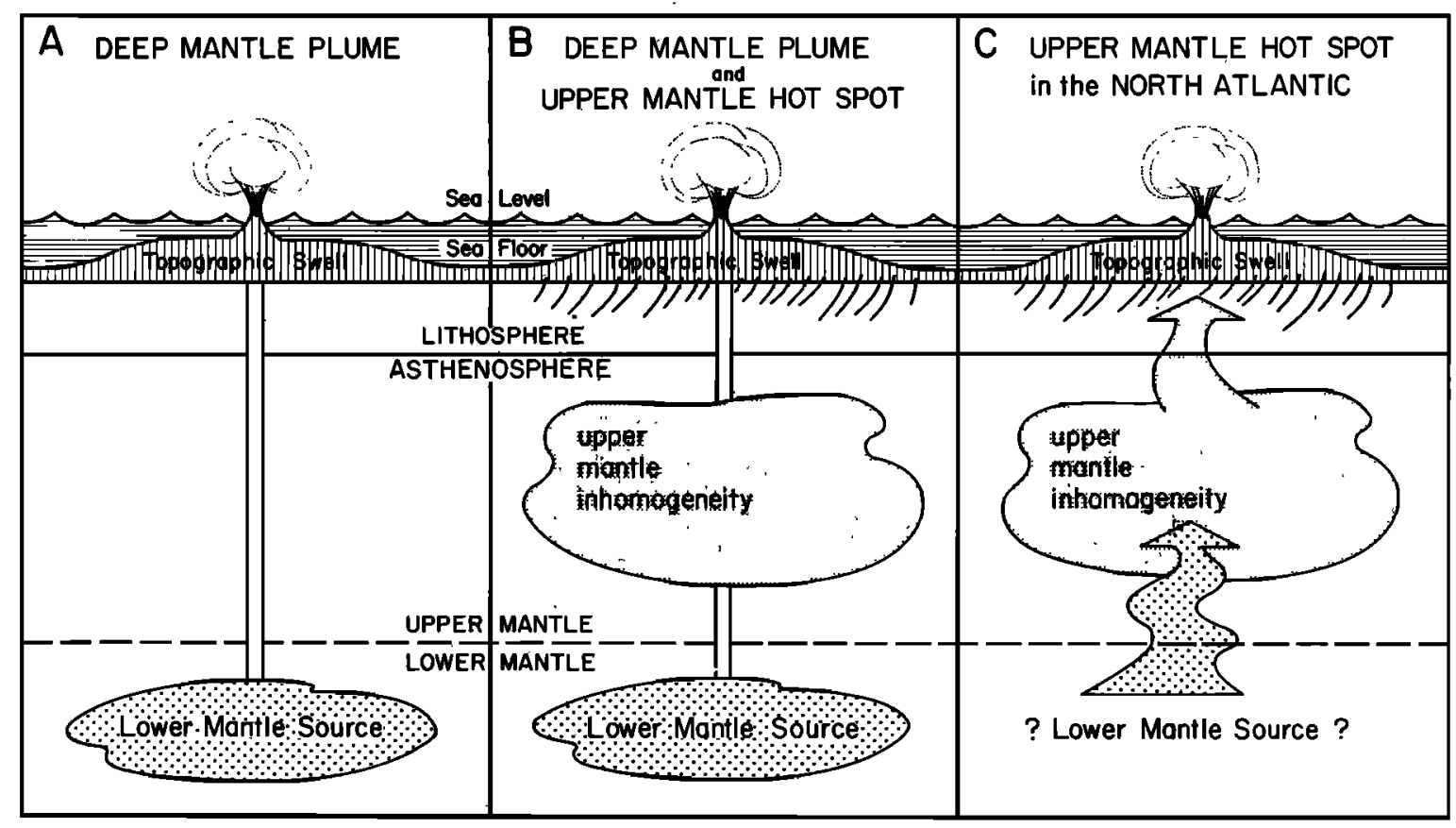

Fig. 11. Sketches showing possible simple models for the deep structure associated with areas of unusual volcanic activity. Figure $11 a$ shows the deep mantle plume model developed by Morgan [1972] and Schilling [1973]. If such a plume is present in the North Atlantic, then the structure must be as is shown in Figure 11b, where the plume is accompanied by, and presumably responsible for, a low-density 'hot spot' in the asthenosphere. Alternatively, the upper mantle hot spot could be the source of the topographic swell and volcanic activity as sketched in Figure $11 \mathrm{c}$. The models shown in Figures $11 b$ and $11 c$ are compatible with our data. 
It could be argued that this model may be applicable to Iceland and the Azores but not necessarily to areas such as Hawaii. However, the extraordinary quantity of volcanism which has built the Hawaiian Ridge is not the only manifestation of the Hawaii hot spot. The volcanism at Hawaii is at the crest of a broad topographic swell $1500 \mathrm{~km}$ across and $1600 \mathrm{~m}$ high [Betz and Hess, 1942; Watts, 1976], which Watts [1976] argues is balanced by a low-density area of comparable extent in the asthenosphere.

Some support for this model comes from recent geochemical arguments presented by $O^{\prime} N i o n s$ and co-workers. O'Nions et al. [1978] used $\mathrm{Sm}$ and $\mathrm{Nd}$ isotope ratios as well as $\mathrm{Rb}$ and $\mathrm{Sr}$ ratios to argue that virtually all basalts erupted in the oceans, including those in Iceland and Hawaii, are derived from source regions which have been depleted to variable extents of $\mathbf{R b}$ and the light rare earths relative to the bulk earth. Thus according to O'Nions et al. [1978] there are no magmas from a 'primordial' unmodified mantle source being erupted anywhere in the North Atlantic. The Iceland and midocean ridge basalts are both depleted and differ in the degree of depletion rather than in one case tapping a pristine source and in the other a modified depleted source.

In addition, O'Nions et al. [1976] have argued that the geochemical data are incompatible with the binary mixing model proposed by Schilling [1973] and concluded that a better model for the abundance patterns found in the North Atlantic is a single chemically inhomogeneous source region which might be equivalent to our anomalous region in the upper mantle. The model of an inhomogeneous low-velocity zone which serves as the source of both the midocean ridge and Iceland basalts is compatible with the gravity data.

Whatever form the mechanism takes, our results imply that a distinct, well-defined region of lowered densities exists to a depth of several hundred kilometers in the upper mantle beneath the North Atlantic and that this area appears to have maintained its identity for a period of the order of $60 \mathrm{~m} . \mathrm{y}$.

If the excess elevation of the North Atlantic is thermal in origin, it will be accompanied by lowered densities in the upper mantle. The density difference in relation to other areas is small but is present over a large area, so it might be discernible by seismic techniques. Published results of studies of seismic velocities in the mantle beneath the anomalous area in the North Atlantic through the use of either $P$ wave [Tryggvason, 1964; Long and Mitchell, 1970] or ScS [O kal and Anderson. 1975; Sipkin and Jordan, 1975] arrival time residuals are presently only applicable to the area beneath the immediate vicinity of Iceland. Although the direct applicability of these results to the rest of the region is doubtful, they do show lowered velocities extending to a depth of several hundred kilometers under Iceland.

\section{CONClusions AND Summary}

We have examined the gravity field of the North Atlantic Ocean using $1^{\circ} \times 1^{\circ}$ and $5^{\circ} \times 5^{\circ}$ average free air gravity anomalies. The $1^{\circ} \times 1^{\circ}$ averages contain substantial information on relatively short wavelength surface features such as fracture zones and seamounts. These anomalies are, for the most part, averaged out in the $5^{\circ} \times 5^{\circ}$ average anomalies which bring out the regional pattern.

The major feature of the regional gravity field in the North Atlantic is a distinct boundary near $30^{\circ} \mathrm{N}$ which is present in both depth and gravity anomalies (profile $h$, Figure 5). North of this latitude the gravity field is characterized by large positive anomalies which are nearly constant along isochrons.
When the midocean ridge anomaly [Cochran and Talwani, $1977]$ is removed, the residual gravity field north of the $30^{\circ} \mathrm{N}$ boundary takes the form of a very broad high centered near or slightly east of the ridge axis. The depths within this area are consistently shallow, but the $5^{\circ} \times 5^{\circ}$ average residual depth anomalies vary greatly from a few hundred meters near the Charlie Gibbs fracture zone to a few thousand meters near Iceland and the Azores.

There is therefore a correlation between the residual gravity anomalies and the residual depth anomalies in the sense that they both are consistently positive within a well-defined region. There is not, however, a direct relationship between the two parameters within the area. In particular, the depth anomalies vary by several thousand meters, and these variations are not reflected in the gravity field.

We used three-dimensional spherical earth models to investigate simple compensated mass distributions which could explain the observed patterns of gravity and depth anomalies in the North Atlantic. Common characteristics of the acceptable family of models are that most of the compensation of the depth anomalies occurs at shallow depths but that in the anomalous region north of the $30^{\circ} \mathrm{N}$ boundary a portion of the compensation must be distributed to depths of several hundred kilometers and that the deep portion of the mass deficiency must be nearly uniform throughout the area. Our results are in agreement with earlier findings that normally the midocean ridges are compensated at a depth less than about a hundred kilometers. However, the abnormally high gravity anomalies over the Mid-Atlantic Ridge suggest a deeper compensation in this region.

The model studies are limited by the facts that they assume a compensated mass distribution and that they are static models concerned with the distribution of mass and thus do not explicitly include any dynamic effects. However, it is possible to infer from our results that a distinct area of lowered densities exists to a depth of several hundred kilometers beneath the North Atlantic.

We suggest that the low densities could result from a modest increase of about $75^{\circ} \mathrm{C}$ in the temperature of the upper mantle. We speculate that the source of the increased temperatures could be related to an inhomogeneity in the lower mantle resulting in a greater than normal heat transport from the lower to the upper mantle beneath a well-defined area of the North Atlantic Ocean.

\section{Appendix: Details of Gravity Model Calculations}

The input data for the spherical earth model calculations are averages over $1^{\circ} \times 1^{\circ}$ squares of depth, sediment thickness, and lithospheric age. As a result, the shallow structure and its compensation can be described in terms of $1^{\circ} \times 1^{\circ}$ prisms. The gravity effect of each prism was computed by using an expression for the gravity effect of a radial mass line on a sphere.

The integral to be solved is

$$
\Delta g=k \rho \sin \Theta d \Theta d \psi \int_{a+h_{1}}^{a+h_{1}}\left(\frac{R^{2} a}{p^{3}}-\frac{R^{3} \cos \Theta}{p^{3}}\right) d R
$$

where $\Theta$ is the angular distance from the point at which the gravity is measured to the location of the mass line, $a$ is the radius of the earth, $R$ is the distance from the center of the earth to the mass element, $p$ is the linear distance from the measurement point to the mass element, $h_{1}$ and $h_{2}$ are the elevation of the top and bottom of the mass line relative to the 
surface of the earth, and $d \Theta$ and $d \psi$ are the angular dimensions of the radial mass prism. The solution of this integral for the gravity effect of a radial mass line was first obtained by $K u k k a$ mäki [1955] and is given by equation (77) of Talwani [1973]. The derivation of Kukkamäki's expression is very similar to that of the more familiar Cassinis' formula for a spherical cap [Cassinis et al., 1937]. In applying Kukkamäki's expression, allowance must be made for the fact that the mass line is situated below rather than above the earth's surface.

The approximation of a $1^{\circ} \times 1^{\circ}$ prism as a radial mass line is not good if the mass line is too near the point at which the computation is made. Figure 12 shows the percentage error in computing the gravity effect of a $1^{\circ} \times 1^{\circ}$ square as a radial mass line as a function of the angular distance between the computation point and the center of the $1^{\circ} \times 1^{\circ}$ square for two different prisms. The error was calculated by comparing the gravity effect obtained by approximating the $1^{\circ} \times 1^{\circ}$ square by a single mass line to that obtained by dividing it into 400 subsquares, approximating each of them as a radial mass line, and summing their gravity effects.

It was necessary therefore to subdivide the $1^{\circ} \times 1^{\circ}$ data squares into subsquares when they were near the point at which the computation was made. The gravity effect of each subsquare was then approximated by a radial mass line at its axis. The number of subsquares was chosen to keep the error in calculating the gravity effect below $1 \%$.

The gravity anomalies were calculated at the corners of data squares in order to keep the minimum distance from the point of computation to the center of the data squares as large as possible. Even so, it was found that a prohibitive number of subsquares were required to obtain acceptable accuracy for the four data squares immediately adjacent to the computation point. Therefore the gravity effect of the adjacent $1^{\circ} \times 1^{\circ}$. squares was computed by using expressions for the gravity effect of a rectangular parallelopiped given by equations (21) and (24) of Talwani [1973]. The parallelopipeds were 'lowered' according to the method of Takin and Talwani [1966] to allow for the curvature of the earth. The center of gravity of each parallelopiped was used as a reference distance in lowering.

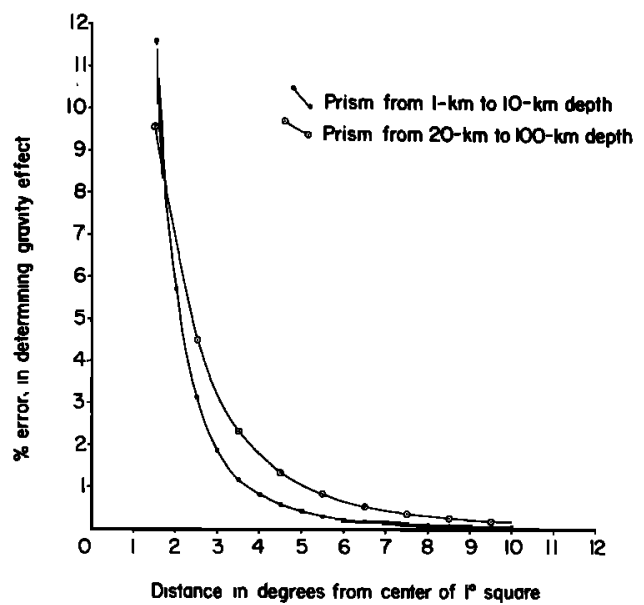

Fig. 12. Percentage error in computing the gravity effect of a $1^{\circ} \mathrm{X}$ $1^{\circ}$ prism as a radial mass line by using an expression of Kukkamäki [1955]. The error is plotted as a function of the angular distance from the center of the $1^{\circ} \times 1^{\circ}$ prism. Errors are shown for two prisms located at different depths. The error was calculated by comparing the result obtained by approximating the $1^{\circ} \times 1^{\circ}$ square with a single radial mass line to that obtained by dividing it into 400 subsquares and approximating each of them by a radial mass line.
Data squares corresponding to shallow structure above about 20-km depth were subdivided into nine parallelopipeds. A single parallelopiped was used for the deeper structure.

Economy in computing time was obtained by combining 25 $1^{\circ} \times 1^{\circ}$ squares into a single $5^{\circ} \times 5^{\circ}$ square when the angular distance from the computation point to the center of the $5^{\circ} \times$ $5^{\circ}$ square was greater than $10^{\circ}$. This was done only if the $1^{\circ} \times$ $1^{\circ}$ squares within the $5^{\circ} \times 5^{\circ}$ square were either all oceanic or all continental so that they all have a similar crustal structure.

Acknowledgments. R. K. O'Nions and A. B. Watts reviewed the manuscript and offered useful criticisms and suggestions. Comments by R. N. Anderson, P. Dehlinger, D. W. Forsyth, and D. E. Hayes were also very helpful. This research was supported by National Science Foundation grants GA-27281 and DES-71-00214 and by $O$ fice of Naval Research contracts N00014-67-A-0108-0004 and N00014-75-C-0210. Lamont-Doherty Geological Observatory contribution 2705.

\section{REFERENCES}

Artyushkov, E. V., Rheological properties of the crust and upper mantle according to data on isostatic movements, J. Geophys. Res. 76, 1376-1390, 1971 .

Betz, F., and H. H. Hess, The floor of the North Pacific Ocean, Geogr. Rev., 32, 99-116, 1942.

Cassinis, G., P. Dore, and S. Ballerin, Fundamental tables for reducing gravity observed values, Publ. 13, Reale Comm. Geod. Italy, Milan, 1937.

Cochran, J. R., and M. Talwani, Free air gravity anomalies in the world's oceans and their relationship to residual elevation, Geophys. J. Roy. Astron. Soc., 50, 495-552, 1977.

Ewing, M., G. Carpenter, C. Windisch, and J. Ewing, Sediment distribution in the oceans: The Atlantic, Geol. Soc. Amer. Bull., 84, 7188, 1973.

Green, D. H., Composition of basaltic magmas as indicators of conditions of origin: Applications to oceanic volcanism, Phil. Trans. Roy. Soc. London, 268.707-725, 1971.

Heirtzler, J. R., G. O. Dickson, E. M. Herron, W. C. Pitman III, and $X$. Le Pichon, Marine magnetic anomalies, geomagnetic field reversals, and motions of the ocean floor and continents, J. Geophys. Res., 73, 2119-2136, 1968.

Kukkamäki, T. J., Gravimetric reductions with electronic computers, Publ. 30, 9 pp., Isostatic Inst. of the Int. Ass. of Geod., Helsinki, 1955.

Lambeck, K., Gravity anomalies over ocean ridges, Geophys. J. Roy. Astron. Soc., 30, 37-54, 1972.

Langseth, M. L., and G. W. Zielinski, Marine heat flow measurements in the Norwegian-Greenland Sea and in the vicinity of Iceland, in Geodynamics of Iceland and the North Atlantic Area, edited by L. Kristjansson, pp. 277-295, D. Reidel, Hingham, Mass., 1974.

Larson, R. L., and T. W. C. Hilde, A revised time scale of magnetic reversals for the Early Cretaceous and Late Jurassic, J. Geophys. Res., 80, 2586-2594, 1975.

Larson, R. L., and W. C. Pitman III, World-wide correlations of Mesozoic magnetic anomalies and their implications, Geol. Soc. Amer. Bull., 83, 3645-3662, 1972.

Long, R. E., and M. G. Mitchell, Teleseismic $P$-wave delay time in Iceland, Geophys. J. Roy. Astron. Soc., 20, 41-48, 1970.

McKenzie, D. P., and N. O. Weiss, Speculations on the thermal and tectonic history of the Earth, Geophys. J. Roy. Astron. Soc., 42, 131174, 1975.

McKenzie, D. P., J. M. Roberts, and N. O. Weiss, Convection in the Earth's mantle: Towards a numerical simulation, J. Fluid Mech., 82, 465-538, 1974

Morgan, W. J., Deep mantle convection plumes and plate motions, Amer. Ass. Petrol. Geol. Bull., 56. 203-213, 1972.

Okal, E. A., and D. L. Anderson, A study of lateral inhomogeneities in the upper mantle by multiple $S c S$ travel-time residuals, Geophys. Res. Lett., 2, 313-316, 1975.

O'Nions, R. K., R. J. Pankhurst, and K. Gronvold, Nature and development of basalt magma sources beneath Iceland and the Reykjanes Ridge, J. Petrol., 17, 315-338, 1976.

O'Nions, R. K., N. M. Evensen, P. J. Hamilton, and S. P. Carter, Melting of the mantle past and present: Isotope and trace element evidence, Phil. Trans. Roy. Soc. London, Ser. A, 258, 547-559, 1978. 
Parker, R. L., and D. W. Oldenberg, A thermal model for oceanic ridges, Nature, 247, 137-139, 1973.

Pitman, W. C., III, and M. Talwani, Sea-floor spreading in the North Atlantic, Geol. Soc. Amer. Bull., 83, 619-646, 1972.

Schilling, J.-G., Iceland mantle plume: Geochemical study of the Reykjanes Ridge, Nature, 242, 565-571, 1973.

Sclater, J. G., and J. Francheteau, The implications of terrestrial heat flow observations on current tectonic and geophysical models of the crust and upper mantle of the Earth, Geophys. J. Roy. Astron. Soc., 20, 509-542, 1970.

Sclater, J. G., R. N. Anderson, and M. C. Bell, The elevation of ridges and the evolution of the Central Eastern Pacific, J. Geophys. Res., $76,7888-7915,1971$.

Sclater, J. G., L. A. Lawver, and B. Parsons, Comparison of longwavelength residual elevation and free air gravity anomalies in the North Atlantic and possible implications for the thickness of the lithospheric plate, J. Geophys. Res., 80, 1031-1052, 1975.

Sipkin, S. A., and T. H. Jordan, Lateral heterogeneity of the upper mantle determined from the travel time of $S C S, J$. Geophys. Res., 80 , 1474-1484, 1975.

Takin, M., and M. Talwani, Rapid computation of the gravitational attraction of topography on a spherical Earth, Geophys. Prospect., 14, 119-142, 1966.

Talwani, M., Computer usage in the computation of gravity anomalies, in Methóds in Computational Physics, 13, edited by B. Bolt, pp. 343-389, Academic, New York, 1973.
Talwani, M., and X. Le Pichon, Gravity field over the Atlantic Ocean, in The Earth's Crust and Upper Mantle, Geophys. Monogr. Ser., vol. 13, edited by P. J. Hart, pp. 341-351, AGU, Washington, D. C., 1969.

Talwani, M., H. R. Poppe, and P. D. Rabinowitz, Gravimetrically determined geoid in the western North Atlantic, Sea Surface Topography from Space, vol. 2, Tech. Rep. ERL-228-AOML 7-2, pp. 1-34, Nat. Oceanic and Atmos. Admin., Boulder, Colo., 1972.

Tryggvason, E., Arrival times of $P$-waves and upper mantle structure, Bull. Seismol. Soc. Amer., 54, 727-736, 1964.

Uchupi, E., Bathymetric atlas of the Atlantic, Caribbean and Gulf of Mexico, Ref. 71-72, Woods Hole Oceanogr. Inst., Woods Hole, Mass., 1971.

Walcott, R. I., Structure of the Earth from glacio-isostatic rebound, Annu. Rev. Earth Planet. Sci. 1, 39-62, 1973.

Watts, A. B., Gravity and bathymetry in the Central Pacific Ocean, $J$. Geophys. Res., 8I, 1533-1553, 1976.

Williams, D. L., and R. P. Von Herzon, Heat loss from the Earth: New estimate, Geology, 2, 327-328, 1974.

Wyllie, P. J., Role of water in magma generation and initiation of diapiric uprise in the mantle, J. Geophys. Res., 76, 1328-1338, 1971.

(Received July 29, 1977;

revised February 10, 1978; accepted May 24, 1978.) 